\title{
COVID-19 Therapeutic Options Under Investigation
}

\author{
Malak Kaddoura ${ }^{1,2 \ddagger}$, Malak Allbrahim ${ }^{1,2 † \neq}$, Ghina Hijazi ${ }^{1,2}$, Nadia Soudani ${ }^{1,2}$, \\ Amani Audi ${ }^{1,2}$, Habib Alkalamouni ${ }^{1,2}$, Salame Haddad ${ }^{1,2}$, Ali Eid $^{3 *}$ \\ and Hassan Zaraket ${ }^{1,2 * t}$
}

${ }^{1}$ Department of Experimental Pathology, Immunology \& Microbiology, Faculty of Medicine, American University of Beirut, Beirut, Lebanon, ${ }^{2}$ Center for Infectious Disease Research, Faculty of Medicine, American University of Beirut, Beirut, Lebanon, ${ }^{3}$ Department of Pharmacology and Toxicology, Faculty of Medicine, American University of Beirut, Beirut, Lebanon

\section{OPEN ACCESS}

Edited by:

Fatih M. M. Uckun,

Reven Pharmaceuticals, United States

Reviewed by:

Chris R. Triggle,

Weill Cornell Medicine-Qatar, Qatar

Sandra Donnini,

University of Siena, Italy

*Correspondence:

Ali Eid

ae81@aub.edu.Ib

Hassan Zaraket

hz34@aub.edu.Ilb

tORCID:

Malak Allbrahim

orcid.org/0000-0002-8801-5228

Hassan Zaraket

orcid.org/0000-0003-3807-6409

${ }^{\ddagger}$ These authors have contributed equally to this work

Specialty section: This article was submitted to Translational Pharmacology, a section of the journal

Frontiers in Pharmacology

Received: 22 May 2020

Accepted: 22 July 2020

Published: 06 August 2020

Citation:

Kaddoura M, Allbrahim M, Hijazi G, Soudani N, Audi A, Alkalamouni $\mathrm{H}$, Haddad S, Eid A and Zaraket $H$ (2020) COVID-19 Therapeutic Options Under Investigation.

Front. Pharmacol. 11:1196. doi: 10.3389/fphar.2020.01196
Since its emergence in China in December 2019, COVID-19 has quickly spread around the globe causing a pandemic. Vaccination or the development of herd immunity seems the only way to slow down the spread of the virus; however, both are not achievable in the near future. Therefore, effective treatments to mitigate the burden of this pandemic and reduce mortality rates are urgently needed. Preclinical and clinical studies of potential antiviral and immunomodulatory compounds and molecules to identify safe and efficacious therapeutics for COVID-19 are ongoing. Two compounds, remdesivir, and dexamethasone have been so far shown to reduce COVID-19-associated death. Here, we provide a review of the potential therapeutic agents being considered for the treatment and management of COVID-19 patients.

Keywords: SARS-CoV-2, COVID-19, antivirals, adjunctive therapy, therapeutics

\section{INTRODUCTION}

The emergence of viral diseases causing respiratory illnesses, and thus threatening human health continues to be a critical threat to public health and the economy. During the last two decades, four major viral outbreaks were recorded. These are the severe acute respiratory syndrome coronavirus "SARS-CoV-1" (Zhong et al., 2003), influenza A/H1N1 (H1N1pdm09) (Dotis and Roilides, 2009), Zika virus (Fauci and Morens, 2016) and the Middle East respiratory syndrome coronavirus "MERS-CoV" (Zaki et al., 2012). H1N1pdm09 and Zika viruses became pandemic, SARS-CoV-1 vanished, while MERS-CoV continues to cause infections but is largely contained.

In December 2019, an outbreak of pneumonia of unknown etiology was reported in Wuhan, China (World Health Organization). A novel coronavirus (CoV), initially named 2019-nCoV, was isolated and identified as the culprit (Zhu et al., 2020). On February 11, 2020, the illness associated with this viral infection was given the name COVID-19 "COronaVIrus Disease 2019" by the World Health Organization (WHO). Owing to its similarity to SARS-like CoVs, the 2019-nCoV has been renamed by the International Committee on Taxonomy of Viruses (ICTV) as SARS-CoV-2. On March 11, 2020, WHO Director-General Tedros Adhanom Ghebreyesus declared COVID-19 a global pandemic (World Health Organization, 2020b).

SARS-CoV-2 is a highly contagious virus that continues to spread at an unprecedented rate; globally confirmed cases exceeded 16 million of which more than 650000 resulted in death, as of the 29th of July (World Health Organization, 2020c). 
The basic reproduction number of COVID-19 has been estimated at 2 to 2.5 (World Health Organization, 2020a). SARS-CoV-2 has a median incubation period of 5.1 days and 97.5\% of symptomatic patients will develop symptoms within 11.5 days. Moreover, $1 \%$ of patients will become symptomatic after 14 days of exposure (Lauer et al., 2020). Patients infected with SARS-CoV-2 mainly experience mild symptoms including fever, cough, fatigue, loss of appetite, difficulty breathing, and muscle pain (Singhal, 2020). Digestive symptoms, such as loss of appetite, nausea, vomiting, diarrhea, and abdominal pain, have also been reported among COVID-19 patients (Pan et al., 2020). Other symptoms such as anosmia or ageusia were also reported among COVID-19 patients (Giacomelli et al., 2020). Skin manifestations including erythematous rash urticaria and pruritus lesions, particularly among young individuals have been also associated with COVID-19 (Recalcati, 2020; Tao et al., 2020). Unfortunately, SARS-CoV-2 infection might result in more severe complications including severe pneumonia and acute respiratory distress syndrome, and may also lead to death (Wang L. et al., 2020).

CoVs are enveloped, positive-sense, single-stranded RNA viruses $(\sim 30 \mathrm{~kb})$ with a $5^{\prime}$-cap structure and $3^{\prime}$-poly-A tail. Their name originates from the Latin word coronam which means crown, representing their crown-like morphology under the microscope. They belong to the Orthocoronavirinae subfamily (Coronaviridae family, Nidovirales order), which includes four genera; Alphacoronavirus and Betacoronavirus (infecting only mammals), Gammacoronavirus and Deltacoronavirus (mainly infecting birds). The Betacoronavirus genus to which SARS-CoV-2 belongs is divided into five lineages (Woo et al., 2012).

To date, seven human coronaviruses (HCoVs) have been detected. The common HCoVs [HCoV-OC43 and HCoV-HKU1 (betaCoVs, A lineage), HCoV-229E, and HCoV-NL63 (alphaCoVs)] usually cause mild self-limiting upper respiratory tract illnesses in immunocompetent individuals. But they can result in lower respiratory tract symptoms in immuno compromised patients and the elderly (Trombetta et al., 2016). The highly pathogenic SARS-CoV-1, SARS-CoV-2 (betaCoVs of the $\mathrm{B}$ lineage), and MERS-CoV (betaCoV of the $\mathrm{C}$ lineage) cause mild to severe pulmonary and extra-pulmonary disease (Su et al., 2016; Chen Y. et al., 2020).

SARS-CoV-2 genome is made up of $\sim 30$ kilobases (Chen L. et al., 2020; Zhou P. et al., 2020), and shares 96.2\% identity with bat $\mathrm{CoV}$ isolate RaTG13, suggesting a bat origin for this virus ( $\mathrm{Lu}$ et al., 2020; Zhou P. et al., 2020; Zhu et al., 2020). Aside from RaTG13, the Pangolin-CoV was very closely related to SARS$\mathrm{CoV}-2$, sharing $91 \%$ nucleotide similarity thereby suspecting that pangolin might be the intermediate host $(22,23)$. Moreover, SARS-CoV-2 has about $79 \%$ and $50 \%$ nucleotide sequence identity with SARS-CoV-1 and MERS-CoV, respectively (Zhou P. et al., 2020). Like other betacoronaviruses, SARS-CoV-2 has a 5' long nonstructural polyprotein (ORF1ab), and four major structural proteins (spike glycoprotein $(\mathrm{S})$, envelope protein $(\mathrm{E})$, matrix protein (M) and nucleocapsid protein(N)) (Phan, 2020). Importantly, genetic analysis of SARS-CoV-2 from different countries reveals that the virus has diversified into several genetic clades (www.nextstrain.org/ncov/global).

There is no doubt that the development of vaccines or antiviral drugs is critical for mitigating the burden of the COVID-19 pandemic (Petherick, 2020). Ongoing preclinical and clinical studies aim to investigate the safety and efficacy of existing molecules or repurposed drugs in the treatment and management of COVID-19. This review focuses on the potential antivirals and adjunctive therapies that are being investigated as therapeutic tools in the fight against COVID-19.

\section{SARS-Like Coronaviruses Lifecycle}

SARS-CoV-2 virions are studded with spike (S) glycoproteins. The $S$ protein serves as a primary target for the host-generated antibody response, entry inhibitors, and vaccines due to its role in viral attachment, fusion, and entry (Du et al., 2009; Yuan et al., 2020). It mediates viral entry into host cells by first binding to the host cell via its receptor-binding domain (RBD) in the S1 subunit and then mediating the fusion between the viral and host membranes through the S2 subunit (Liu et al., 2004; Li et al., 2005). Similar to SARS-CoV-1, SARS-CoV-2 also recognizes angiotensin-converting enzyme 2 (ACE2) as its host receptor (Li et al., 2003).

Interestingly, SARS-CoV-1 RBD-specific polyclonal antibodies could cross-neutralize SARS-CoV-1 and SARS-CoV-2 pseudovirus infection, by blocking their entry into human ACE2 (hACE2)expressing cells, suggesting the potential to develop RBD-based vaccine for prevention of infection by SARS-CoV-2 (Tai et al., 2020). Following receptor binding, the virus must gain access to the host cell cytosol. This is accomplished by acid-dependent proteolytic cleavage of $\mathrm{S}$ protein by a lysosomal cathepsin $\mathrm{L}$, followed by fusion of the viral and cellular membranes (Wang et al., 2008). This proteolytic cleavage occurs at two sites, the first at the $\mathrm{S} 1 / \mathrm{S} 2$ site and is important for separating the RBD and fusion domains of the protein; and the second at the S2' site and is important for exposing the fusion peptide (Belouzard et al., 2009). A recent study showed that TMPRSS2-expressing Vero E6 cell line displays enhanced SARS-CoV-2 infection compared to parenteral Vero cells (Matsuyama et al., 2020). Inhibiting TMPRSS2 serine protease blocked the entry of VSV-SARS-2-S pseudotypes, supporting the important role of TMPRSS2 in SARS-CoV-2 entry. Fusion occurs within acidified endosomes, then, releasing the viral genome into the cytoplasm (Fehr and Perlman, 2015). The next step in the virus lifecycle is the translation of the replicase genes from the virion genomic RNA. The replicase gene encodes two large ORFs, ORF1a and ORF1b, which express two coterminal polyproteins, ppla and pplab (Baranov et al., 2005). The main protease $\mathrm{M}^{\text {pro }}$, also called $3 \mathrm{CL}^{\text {pro }}$, is considered a highly promising target to treat different coronaviruses strains (Zhang L. et al., 2020). This protease, in addition to the papainlike protease(s), is crucial for polyprotein processing (Hilgenfeld, 2014; Zhang L. et al., 2020). Therefore, blocking the viral replication is possible by targeting this enzyme, and its inhibition is not expected to be harmful because there are no identified human proteases that possess the same cleavage specificity. 
The next step in the virus lifecycle, after the translation and assembly of the viral replicase complexes, is the viral RNA synthesis. This viral RNA synthesis produces both genomic and sub-genomic RNAs. Sub-genomic RNAs serve as mRNAs for the structural and accessory genes. These genes reside downstream of the replicase ORF. Through negative-strand intermediates, genomic and subgenomic RNAs are generated (Fehr and Perlman, 2015). Following replication and subgenomic RNA synthesis, the viral structural proteins, $\mathrm{S}, \mathrm{E}$, and $\mathrm{M}$ are translated and inserted into the endoplasmic reticulum (ER). These proteins move along the secretory pathway into the ER-Golgi intermediate compartment (ERGIC) (He et al., 2014). In this intermediate compartment, the mature virions are produced by budding of the viral genomes encapsidated by $\mathrm{N}$ protein into its membranes holding the viral structural proteins (de Haan and Rottier, 2005). M and E proteins form the viral envelope and are sufficient for the generation of virus-like particles (VLP). Moreover, $\mathrm{N}$ protein was shown to enhance VLP production, proposing that the fusion of encapsidated genomes into the ERGIC complement envelope formation (Siu et al., 2008). At this level, the inclusion of the S protein into virions takes place but is not needed for assembly. However, this step needs the capacity of this protein to traffic to the ERGIC and interact with the $M$ protein. Once the $M$ protein attaches to the nucleocapsid, the assembly will be accomplished (Hurst et al., 2005). Finally, virions are transported to the cell membrane via transport vesicles and are then liberated by exocytosis (Figure 1).

\section{DRUGS UNDER INVESTIGATION FOR TREATMENT AND MANAGEMENT OF COVID-19}

In this review, we classified the various drugs currently under investigation into three categories: virus targeting, host targeting, and adjunctive therapy. The direct-active antivirals represent a class of drugs that exert its activity by directly targeting viral components thus blocking replication. Host-targeting compounds represent a class of drugs that interfere with host factors crucially required for viral infection and replication. While the disease-modulating adjunctive therapy includes molecules that modulate the host immune response to reduce inflammation. Finally, drugs with more than one mode of action were included in the mixed mode of action category. A summary of all drugs being considered for COVID-19 treatment and management is presented in Table 1. In addition, data available from clinical trials were summarized in Table 2.

\section{Virus Targeting Agents \\ Remdesivir}

Remdesivir (GS-5734) is an investigational monophosphoramidate prodrug of an adenine analog that was originally tested against the Ebola virus in rhesus monkeys (Warren et al., 2016). Biochemical analysis revealed that remdesivir blocks the replication of the Ebola virus by inhibiting its RNA-dependent RNA polymerase
(Tchesnokov et al., 2019). However, based on an interim analysis of the PALM trial, remdesivir was dropped from clinical trials after showing inferior outcomes to REGN-EB3, a cocktail of three monoclonal antibodies (Mulangu et al., 2019). Besides the Ebola virus, remdesivir showed in vitro and in vivo inhibitory activity against the Nipah virus (Lo et al., 2017; Lo et al., 2019). In 2017, in vitro studies (using primary human airway epithelial cells) revealed that remdesivir also possesses a broad-spectrum antiviral activity against epidemic and zoonotic CoVs including MERS-CoV and SARS-CoV-1 (Sheahan et al., 2017). This anti-CoV-activity is achieved through inhibiting the RNA polymerase and early termination of transcription (Agostini et al., 2018). Moreover, in vivo investigations, using a SARS-CoV-1 mouse model revealed that prophylactic and therapeutic administration of remdesivir resulted in a significant decrease in lung viral titers and mitigation of the disease (Sheahan et al., 2017). Remdesivir exhibits superior in vitro (Calu-3 cells) antiviral activity to lopinavir/ritonavir-alone or in combination with interferon (INF- $\beta$ ) against MERS-CoV. Besides, therapeutic administration of remdesivir acute lung injury in mice but without reducing viral loads (Sheahan et al., 2020a). Remdesivir was also shown to possess prophylactic and therapeutic efficacy against SARS-CoV-2 in rhesus macaque models (de Wit et al., 2020).

Owing to the promising antiviral activity of remdesivir against SARS-CoV-1 and MERS-CoV, it was considered as a potential antiviral drug against SARS-CoV-2. In vitro studies, using Vero E6 cells, revealed a significant reduction in SARSCoV-2 yield with a $50 \%$ effective concentration (EC50) of 0.77 23.15 MM (Choy et al., 2020; Wang M. et al., 2020). Moreover, in silico studies showed that remdesivir could tightly bind SARSCoV-2 RdRps (Elfiky, 2020b). The in vivo efficacy of remdesivir was evaluated rhesus macaques infected with SARS-CoV-2 showing clear clinical benefit with a reduction in viral load and lung damage in treated animals (Williamson et al., 2020, 2). Notably, the treatment of these animals was initiated $12 \mathrm{~h}$ after SARS-CoV-2 inoculation. It remains important to assess whether the clinical benefit can be maintained if treatment was delayed. Early data from the compassionate use of remdesivir revealed that the treatment was associated with clinical improvement in $68 \%$ of hospitalized patients with severe COVID-19 (Grein et al., 2020, 19). However, this study was limited to being observational and non-randomized. A randomized double-blinded multicenter trial that was conducted among adult patients infected with SARS-CoV-2 showed that the administration of remdesivir did not possess any significant therapeutic advantage. Even though the early administration of remdesivir shortened the time needed for clinical improvement, it did not reach statistical significance due to the small sample size which led to the termination of the study (Wang Y. et al., 2020). Preliminary data of a randomized trial conducted on 1063 COVID-19 patients showed that the use of remdesivir significantly sped up the recovery time by four days (11 days vs 15 days for placebo; relative risk 1.04 [0.91-1.18]; $\mathrm{p}<0.001)$ and reduced the death rate by 14 days (7.1\% vs $11.9 \%$ for placebo; $\mathrm{p}=0.059$ ) (Beigel et al., 2020). Another randomized, open-label, phase 3 trial found that hospitalized patients who did not require mechanical ventilation and received a shorter, 


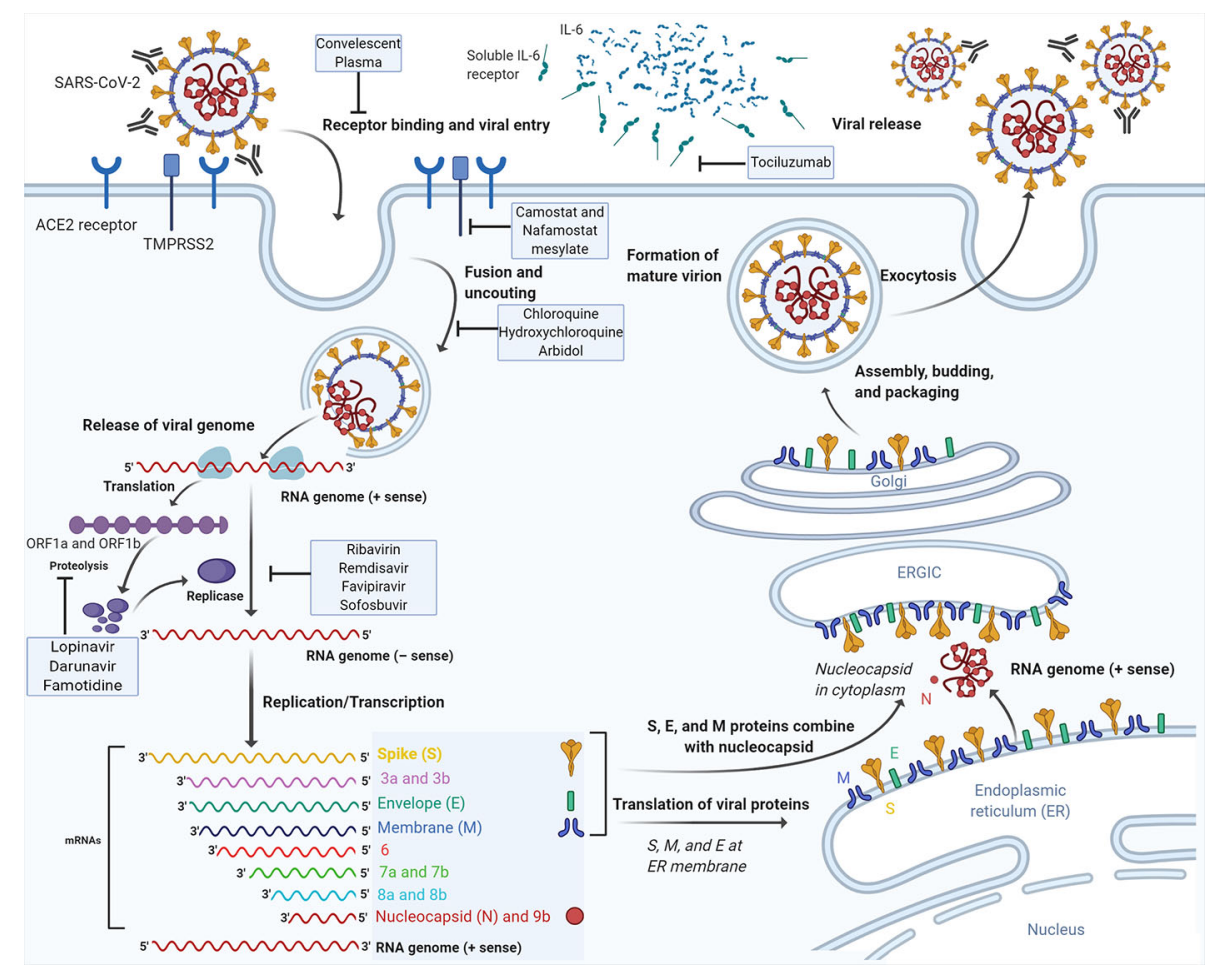

FIGURE 1 | The life cycle of SARS-CoV-2 and the mode of action of potential therapeutic molecules. SARS-CoV-2 enters target cells through an endosomal pathway. The S protein of the virus binds to cellular receptor ACE2. Following the entry of the virus into the host cell, the viral RNA is unveiled in the cytoplasm. ORF1a and ORF1ab are translated to produce pp1a and pp1ab polyproteins, which are cleaved by the proteases that are encoded by ORF1a to yield non-structural proteins that form the RNA replicase-transcriptase complex. The polymerase produces a series of subgenomic mRNAs by discontinuous transcription and finally translated into relevant viral proteins. Viral nucleocapsids are assembled from genomic RNA and N protein in the cytoplasm, followed by budding into the lumen of the ERGIC. Virions are then released from the infected cell through exocytosis. ACE2, angiotensin-converting enzyme 2; ER, endoplasmic reticulum; ERGIC, ERGolgi intermediate compartment. Drugs with potential anti-SARS-CoV-2 activity are depicted on the corresponding stage of the virus life cycle which they are thought to interfere with.

5-day regimen, experienced similar clinical improvement as patients who received a 10-day regimen (Goldman et al., 2020, 19). In this context, on May 1, 2020, the Food and Drug Administration (FDA) has approved the emergency use of remdesivir in SARS-CoV-2-infected patients (Food and Drug Adminstration, 2020). A very recent GILEAD press release report presented new findings regarding remdesivir; a comparative analysis of Phase 3 SIMPLE-Severe trial and a real-world retrospective cohort of patients with severe SARSCoV-2 infection revealed that remdesivir resulted in better improvement and diminished death rate by $62 \%$ compared to standard care (GILEAD, 2020). Simultaneously, several clinical trials are ongoing to assess the safety and efficacy of remdesivir, including two randomized ones.

\section{Lopinavir/Ritonavir}

Lopinavir/ritonavir combination is an FDA-approved drug indicated for the treatment of HIV-1. Lopinavir is an antiretroviral protease inhibitor that undergoes extensive hepatic metabolism. In this context, ritonavir, a protease inhibitor with a CYP3A4 inhibitory activity, is used in combination with lopinavir to increase its bioavailability and boost its antiviral activity (Food and Drug Administration; De Clercq, 2009). In vitro, lopinavir significantly inhibits the replication of MERSCoV, SARS-CoV-1, and HCoV-229E (Chen et al., 2004; Chu et al., 2004; de Wilde et al., 2014). Treatment of MERS-CoVinfected common marmoset with lopinavir/ritonavir resulted in improved clinical outcomes and reduced lung viral loads (Chan et al., 2015). Clinical trials investigating the efficacy of lopinavir/ ritonavir, combined with INF- $\beta$ 1b against MERS-CoV (NCT02845843) is ongoing.

With the emergence of SARS-CoV-2, lopinavir/ritonavir was quickly considered as one of the potential treatment options. Lopinavir inhibits the replication of SARS-CoV-2 virus in Vero E6 cells with an EC50 of $26.63 \mu \mathrm{M}$ (Choy et al., 2020). Kang et al. further showed that lopinavir/ritonavir possesses significant inhibitory activity against SARS-CoV-2 in vitro at concentrations $(7 / 1.75 \mu \mathrm{g} / \mathrm{mL})$ equivalent to their steady-state plasma levels (Kang et al., 2020). Clinically, a retrospective analysis of hospitalized COVID-19 patients showed that only early administration ( $\leq 10$ days from disease onset) of lopinavir/ ritonavir was associated with shorter duration of virus shedding (Yan et al., 2020). These observations were not supported by the stronger evidence originating from 
TABLE 1 | Potential SARS-CoV-2 therapeutic agents.

Compound/drug

\section{Virus targeting agents}

Remdesivir

Inhibits RNA-dependent RNA polymerase

Lopinavir/Ritonavir (Kaletra) Protease inhibitor with a CYP3A4 inhibitory activity

Favipiravir
Ribavirin
Famotidine
EIED 2801
Oseltamivir
Sofosbuvir
Penciclovir
Azvudine
Triazavirin
ACE2 decoy receptor

Host-targeting agents

Azithromycin

Ivermectin

Nafamostat and Camostat

Teicoplanin

Nitazoxanide

Drugs with mixed action

Umifenovir

Chloroquine phosphate and hydroxychloroquine
Inhibits RNA-dependent RNA polymerase

Blocks viral RNA synthesis and viral mRNA capping

Histamine-2 $(\mathrm{H} 2)$ receptor antagonist

$3 \mathrm{CL}^{\text {pro }}$ targeting

Impairs viral replication by incorporating into the genome of the newly formed virions

Inhibits neuraminidase enzyme

Inhibits RNA-dependent RNA polymerase

Inhibits viral DNA polymerase

Inhibiting nucleoside reverse-transcriptase

Inhibits RNA synthesis

ACE2 antagonist

Stimulates the interferon pathway

Interferes with virus internalization

Impairs nuclear import by interacting with importin (IMP) $\alpha / \beta 1$ heterodimer

Inhibits fusion-activation of the virus through inhibition of the host protease (TMPRSS2)

Suppresses the entry by blocking the activity of cathepsin $L$ in the late endosome/ lysosome

Blocks viral entry and replication

Inhibits the production of pro-inflammatory cytokines

-Inhibits membrane fusion through interacting with the viral glycoproteins

- Elevate endosomal $\mathrm{pH}$

-Hinders the auto-immune response

-Impairing ACE2 terminal glycosylation-Increasing the endosomal pH

\section{Adjunctive therapy}

Immunomodulatory agents

Fingolimod

Thymosin $\alpha 1$

Tocilizumab

Bevacizumab

Colchicine

Methylprednisolone

Dexamethasone

Convalescent plasma

Targets sphingosine-1-phosphate (S1P) receptors and alters the signaling of the S1P pathway

Triggers lymphocyte maturation

Enhances T cell activation

Recombinant anti-human interleukin-6 receptor (IL-6R) monoclonal antibody

Humanized monoclonal antibody against the angiogenic vascular endothelial growth factor No (VEGF)

Down-regulates multiple inflammatory pathways through tubulin disruption Inhibits microtubule-dependent chemotaxis of neutrophils, generation of leukotrienes and cytokines, phagocytosis, and the (TNF- $\alpha$ )-induced NF- $\kappa B$ pathway

Anti-inflammatory properties at high doses

Anti-inflammatory properties

Provides passive immunization
Yes

EC50 $=0.77-23.15$

$\mathrm{MM}$ Vero E6 cells

Yes

EC50 $=26.63 \mu \mathrm{M}$

Vero E6 cells

No

No

No

Yes

$\mathrm{EC50}=0.3 \mu \mathrm{M}$

Vero E6

No

No

Yes

EC50 $=95.96 \mu \mathrm{M}$

Vero E6

No

No

Yes

6-100 $\mu \mathrm{g} / \mathrm{ml}$

Yes

Yes

$\mathrm{EC50}=2 \mu \mathrm{M}$

Vero-hSLAM cells

Yes

$\mathrm{EC50}=22.50 \mu \mathrm{M}$

Vero E6 cells

Yes

$\mathrm{EC} 50=1.66 \mu \mathrm{M}$

Vero E6 cells

Yes

$\mathrm{EC50}=2.12 \mu \mathrm{M}$

Vero E6 cells

Yes

$\mathrm{EC50}=4.11 \mu \mathrm{M}$

Vero E6 cells

Yes

CQ EC50 = 1.13-

$5.74 \mu \mathrm{M}$

HCQ EC50 $=0.72$

$\mu \mathrm{M}$

Vero E6 cells
No

No

No

No

No

Not applicable

Not applicable

Not applicable
Yes

Yes

Yes

Yes

Yes Yes

Yes Yes

Yes No

Yes No

Yes No

No No

No No

Yes No

Yes No

Yes No

Yes

No

Yes

No

Yes

No

No

No

Yes

No

Yes

No

Yes

Yes

Yes

No

Yes

No

Yes

No

Yes

No

Yes

Yes

Yes

Yes
Yes
No

Yes 
TABLE 2 | Summary of COVID-19 therapeutics that have completed clinical trials.

\begin{tabular}{|c|c|c|c|c|c|c|}
\hline Ref & Compound & Route & Dosing regimen & Study design & $\begin{array}{l}\text { Evidence } \\
\text { type }^{\#}\end{array}$ & Summary \\
\hline $\begin{array}{l}\text { (Wang Y. } \\
\text { et al., 2020) }\end{array}$ & Remdesivir & Intravenous & $\begin{array}{l}200 \mathrm{mg} \text { on day } 1 \\
\text { followed by } 100 \mathrm{mg} \\
\text { on days } 2-10 \text { in } \\
\text { single daily infusions }\end{array}$ & $\begin{array}{l}\text { Randomized, double- } \\
\text { blind, placebo- } \\
\text { controlled, multicenter } \\
\text { trial }\end{array}$ & Moderate & $\begin{array}{l}\text { Aim: To evaluate the safety and efficacy of remdesivir in } \\
\text { hospitalized adults infected with SARS-CoV- } 2 \text {. } \\
\text { Key findings: No significant difference in improvement time. } \\
\text { Adverse effects: Same as placebo. }\end{array}$ \\
\hline $\begin{array}{l}\text { (Beigel et al., } \\
\text { 2020) }\end{array}$ & Remdesivir & Intravenous & $\begin{array}{l}200 \text { mg on the first } \\
\text { day followed by a } \\
100 \text {-mg once daily } \\
\text { maintenance dose for } \\
\text { up to a } 10 \text { days }\end{array}$ & $\begin{array}{l}\text { Multicenter, } \\
\text { adaptive, randomized, } \\
\text { double-blind, placebo- } \\
\text { controlled trial }\end{array}$ & Strong & $\begin{array}{l}\text { Aim: To evaluate the safety and efficacy of remdesivir in } \\
\text { hospitalized adults infected with SARS-CoV-2. } \\
\text { Key findings: Patients receiving remdesivir recovered faster } \\
\text { than those treated with placebo (median recovery time of } \\
11 \text { days and } 15 \text { days, respectively). The risk of death by } 14 \\
\text { days was less in the remdesivir group compared with the } \\
\text { placebo one; } 7.1 \% \text { and } 11.9 \% \text { respectively. } \\
\text { Adverse effects: Same as placebo. }\end{array}$ \\
\hline $\begin{array}{l}\text { (Cao et al., } \\
\text { 2020) }\end{array}$ & $\begin{array}{l}\text { Lopinavir/ } \\
\text { ritonavir }\end{array}$ & oral & $\begin{array}{l}400 \mathrm{mg} / 100 \mathrm{mg} \\
\text { twice daily for } 14 \\
\text { days }\end{array}$ & $\begin{array}{l}\text { Randomized, } \\
\text { controlled, open-label } \\
\text { trial }\end{array}$ & Moderate & $\begin{array}{l}\text { Aim: To study the efficacy of lopinavir/ritonavir in } \\
\text { hospitalized adult patients with severe COVID-19. } \\
\text { Key findings: No clinical benefit. } \\
\text { Adverse effects: Greater than placebo primarily } \\
\text { gastrointestinal side effects. }\end{array}$ \\
\hline $\begin{array}{l}\text { (Chen C. } \\
\text { et al., 2020) }\end{array}$ & $\begin{array}{l}\text { Favipiravir or } \\
\text { umifenovir }\end{array}$ & Oral & $\begin{array}{l}\text { Favipiravir } 1,600 \mathrm{mg} \\
\text { twice daily } 1 \text { st day } \\
\text { then } 600 \mathrm{mg} \text { twice } \\
\text { daily for } 10 \text { days } \\
\text { vs. umifenovir } 200 \mathrm{mg} \\
\text { three times daily for } \\
10 \text { days }\end{array}$ & $\begin{array}{l}\text { Prospective, } \\
\text { randomized, } \\
\text { controlled, open-label. }\end{array}$ & Moderate & $\begin{array}{l}\text { Aim: To evaluate the clinical efficacy and safety of favipiravir } \\
\text { versus umifenovir as a treatment for COVID-19. } \\
\text { Key findings: No improvement in clinical recovery at day } 7 \text {. } \\
\text { Improved the time to relief for pyrexia and cough compared } \\
\text { to umifenovir. } \\
\text { Adverse effects: raised serum uric acid was more } \\
\text { frequently observed in favipiravir group. }\end{array}$ \\
\hline $\begin{array}{l}\text { (Cai et al., } \\
\text { 2020) }\end{array}$ & Favipiravir & Oral & $\begin{array}{l}\text { Favipiravir } 1,600 \mathrm{mg} \\
\text { twice daily } 1^{\text {st }} \text { day } \\
\text { then } 600 \mathrm{mg} \text { twice } \\
\text { daily for } 14 \text { days + } \\
5 \mathrm{mlU} \text { of IFN- } \alpha \text { twice } \\
\text { daily } \\
\text { vs. } \\
\text { lopinavir/ritonavir } 400 \\
\text { mg/100 mg twice } \\
\text { daily + } 5 \text { mIU of IFN- } \\
\alpha \text { twice daily for } 14 \\
\text { days }\end{array}$ & $\begin{array}{l}\text { Open-label } \\
\text { nonrandomized- } \\
\text { comparative } \\
\text { controlled study }\end{array}$ & Weak & $\begin{array}{l}\text { Aim: To examine the efficacy of favipiravir versus lopinavir/ } \\
\text { ritonavir for the treatment of COVID- } 19 \text {. } \\
\text { Key Findings: FPV showed better therapeutic } \\
\text { responses than LPV/RTV. } \\
\text { Adverse effects: Generally mild but less common in the } \\
\text { favipiravir treated group. }\end{array}$ \\
\hline $\begin{array}{l}\text { (Hung et al., } \\
\text { 2020) }\end{array}$ & Ribavirin & Oral & $\begin{array}{l}400 \mathrm{mg} \text { twice daily for } \\
14 \text { days }\end{array}$ & $\begin{array}{l}\text { Prospective, } \\
\text { randomized, } \\
\text { controlled, open-label } \\
\text { trial }\end{array}$ & Moderate & $\begin{array}{l}\text { Aim: To evaluate the safety and efficacy of IFN-B-1b, } \\
\text { lopinavir/ritonavir, and ribavirin combination. } \\
\text { Key findings: Recovery was accelerated, viral load was } \\
\text { suppressed, hospitalization was shortened and mortality } \\
\text { was reduced after the combination of lopinavir/ritonavir, } \\
\text { ribavirin, and IFN-B-1b compared with to lopinavir/ritonavir } \\
\text { alone (control). } \\
\text { Adverse effects: Same as placebo. }\end{array}$ \\
\hline $\begin{array}{l}\text { (Li Y. et al., } \\
\text { 2020) }\end{array}$ & $\begin{array}{l}\text { Umifenovir or } \\
\text { lopinavir/ritinovir }\end{array}$ & Oral & $\begin{array}{l}\text { Lopinavir } 200 \mathrm{mg} \\
\text { plus ritonavir } 500 \mathrm{mg} \\
\text { twice daily for } 7-14 \\
\text { days } \\
\text { vs. } \\
\text { umifenovir } 200 \mathrm{mg} \\
\text { three times daily for } \\
7-14 \text { days }\end{array}$ & $\begin{array}{l}\text { Open-label } \\
\text { randomized controlled } \\
\text { trial }\end{array}$ & Moderate & $\begin{array}{l}\text { Aim: To explore the efficacy and safety of lopinavir/ritonavir } \\
\text { or umifenovir monotherapy for the treatment of patients } \\
\text { hospitalized with mild/moderate COVID-19. } \\
\text { Key findings: lopinavir/ritonavir or umifenovir monotherapy } \\
\text { offered minimal added benefit compared to standard of } \\
\text { care. } \\
\text { Adverse events: Greater than control with diarrhea being } \\
\text { most common. }\end{array}$ \\
\hline $\begin{array}{l}\text { (Gautret } \\
\text { et al., 2020) }\end{array}$ & HCQ/AZM & Oral & $\begin{array}{l}\text { HCQ } 200 \text { mg three } \\
\text { times daily for } 10 \\
\text { days } \\
\text { Azithromycin } 500 \mathrm{mg} \\
\text { on day } 1 \text { followed by } \\
250 \text { mg daily for four } \\
\text { consecutive days }\end{array}$ & $\begin{array}{l}\text { Open-label non- } \\
\text { randomized clinical } \\
\text { trial }\end{array}$ & Weak & $\begin{array}{l}\text { Aim: To investigate the efficacy of HCQ in COVID-19 } \\
\text { patients and the role of adding AZM } \\
\text { Key findings: Significant reduction in viral load in patients } \\
\text { receiving HCQ alone. } 100 \% \text { recovery in patients receiving a } \\
\text { combination of AZM and HCQ. } \\
\text { Adverse effects: Not described. }\end{array}$ \\
\hline $\begin{array}{l}\text { (Boulware } \\
\text { et al., 2020) }\end{array}$ & $\mathrm{HCQ}$ & Oral & $\begin{array}{l}800 \mathrm{mg} \text { as a first } \\
\text { dose, followed by } \\
600 \mathrm{mg} \text { after } 6 \text { to } 8 \mathrm{~h} \text {, }\end{array}$ & $\begin{array}{l}\text { Randomized, double- } \\
\text { blind, placebo- } \\
\text { controlled trial }\end{array}$ & Strong & $\begin{array}{l}\text { Aim: To assess HCQ as post-exposure (within } 4 \text { days of } \\
\text { exposure) prophylaxis for COVID-19 } \\
\text { Key findings: HCQ did not prevent laboratory confirmed }\end{array}$ \\
\hline
\end{tabular}


TABLE 2 | Continued

\begin{tabular}{|c|c|c|c|c|c|c|}
\hline Ref & Compound & Route & Dosing regimen & Study design & $\begin{array}{l}\text { Evidence } \\
\text { type }^{\#}\end{array}$ & Summary \\
\hline & & & $\begin{array}{l}\text { then } 600 \text { mg daily for } \\
4 \text { days }\end{array}$ & & & $\begin{array}{l}\text { infection or COVID-19 like illness compared to placebo } \\
\text { Adverse effects: Greater than placebo but not serious }\end{array}$ \\
\hline $\begin{array}{l}\text { (Mitjà et al., } \\
\text { 2020) }\end{array}$ & $\mathrm{HCQ}$ & Oral & $\begin{array}{l}800 \text { mg on the first } \\
\text { day, followed by } 400 \\
\text { mg once daily for } 6 \\
\text { days }\end{array}$ & $\begin{array}{l}\text { Multicenter, open } \\
\text { label, randomized } \\
\text { controlled trail }\end{array}$ & Moderate & $\begin{array}{l}\text { Aim: To evaluate the efficacy of early administration of HCQ } \\
\text { in non-hospitalized adults with mild COVID-19 } \\
\text { Key findings: No significant difference in viral load } \\
\text { reduction, risk of hospitalization, and clinical recovery } \\
\text { compared to standard care. } \\
\text { Adverse effects: Same as placebo }\end{array}$ \\
\hline $\begin{array}{l}\text { (Skipper } \\
\text { et al., 2020) }\end{array}$ & $\mathrm{HCQ}$ & Oral & $\begin{array}{l}800 \mathrm{mg} \text { as a first } \\
\text { dose followed by } 600 \\
\text { mg after } 6 \text { to } 8 \text { h, } \\
\text { then } 600 \text { mg daily for } \\
4 \text { days }\end{array}$ & $\begin{array}{l}\text { Randomized, double } \\
\text { blinded, placebo } \\
\text { controlled trial }\end{array}$ & Strong & $\begin{array}{l}\text { Aim: To assess the efficacy of HCQ in decreasing the } \\
\text { disease severity in adult outpatients with early, mild COVID- } \\
19 \\
\text { Key findings: No significant decrease in the severity of } \\
\text { symptoms compared to placebo } \\
\text { Adverse effects: Greater than placebo- none were serious }\end{array}$ \\
\hline $\begin{array}{l}\text { (Deftereos } \\
\text { et al., 2020) }\end{array}$ & Colchicine & Oral & $\begin{array}{l}1.5 \text {-mg loading dose } \\
\text { followed by } 0.5 \mathrm{mg} \\
\text { after } 60 \text { min } \\
\text { and maintenance } \\
\text { doses of } 0.5 \mathrm{mg} \\
\text { twice daily for } 3 \\
\text { weeks }\end{array}$ & $\begin{array}{l}\text { Prospective, open- } \\
\text { label, randomized } \\
\text { clinical trial }\end{array}$ & Moderate & $\begin{array}{l}\text { Aim: To evaluate the effect of treatment with colchicine on } \\
\text { cardiac and inflammatory biomarkers and clinical outcomes } \\
\text { in COVID-19 hospitalized patients } \\
\text { Key findings: Improved time to clinical deterioration. } \\
\text { Adverse effects: Similar to the control group except for } \\
\text { diarrhea being more frequent with colchicine. }\end{array}$ \\
\hline $\begin{array}{l}\text { (The } \\
\text { RECOVERY } \\
\text { Collaborative } \\
\text { Group, 2020) }\end{array}$ & Dexamethasone & $\begin{array}{l}\text { Oral or } \\
\text { intravenous }\end{array}$ & $\begin{array}{l}6 \text { mg once daily for } \\
10 \text { days }\end{array}$ & $\begin{array}{l}\text { Randomized, } \\
\text { controlled, open-label, } \\
\text { adaptive, platform trial }\end{array}$ & Moderate & $\begin{array}{l}\text { Aim: To evaluate dexamethasone in hospitalized COVID-19 } \\
\text { patients. } \\
\text { Key findings: Dexamethasone reduced mortality among } \\
\text { those receiving invasive mechanical ventilation or oxygen } \\
\text { but not among milder cases. } \\
\text { Adverse effects: Not described. }\end{array}$ \\
\hline $\begin{array}{l}\text { (Joyner et al., } \\
\text { 2020) }\end{array}$ & $\begin{array}{l}\text { Convalescent } \\
\text { Plasma }\end{array}$ & Intravenous & $200-500 \mathrm{~mL}$ & Non-randomized & Weak & $\begin{array}{l}\text { Aim: To investigate the safety of convalescent plasma } \\
\text { treatment in hospitalized COVID-19 patients } \\
\text { Key findings: Transfusion of convalescent plasma is safe. } \\
\text { Adverse effects: Frequency of }<1 \% \text { of all transfusions. } \\
\text { Include transfusion-associated circulatory overload (TACO), } \\
\text { transfusion-related acute lung injury (TRALI), severe allergic } \\
\text { transfusion reaction, and death. }\end{array}$ \\
\hline $\begin{array}{l}\text { (Li L. et al., } \\
\text { 2020) }\end{array}$ & $\begin{array}{l}\text { Convalescent } \\
\text { Plasma }\end{array}$ & Intravenous & 4 to $13 \mathrm{ml} / \mathrm{kg}$ & $\begin{array}{l}\text { Open-label, } \\
\text { multicenter, } \\
\text { randomized clinical } \\
\text { trial }\end{array}$ & Moderate & $\begin{array}{l}\text { Aim: To evaluate the efficacy and adverse effects of } \\
\text { convalescent plasma therapy for patients with COVID- } 19 \text {. } \\
\text { Key findings: No statistically significant difference in clinical } \\
\text { improvement within } 28 \text { days. Negative viral PCR } \\
\text { conversion rate was significantly higher in the convalescent } \\
\text { plasma group. } \\
\text { Adverse effects: Reported in two patients. Included chills } \\
\text { and rashes in one patient and shortness of breath, } \\
\text { cyanosis, and severe dyspnea within } 6 \text { h of transfusion in } \\
\text { another one. }\end{array}$ \\
\hline
\end{tabular}

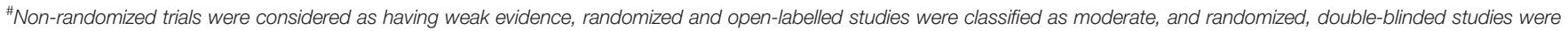
considered strong evidence. Randomized, double blinded studies that could not complete enrollment (underpowered) were downgraded to moderate.

randomized clinical trials that showed a lack of benefit for lopinavir/ritonavir treatment. A randomized, controlled, openlabel trial in China showed that a twice-daily two-week regimen of lopinavir/ritonavir for hospitalized adult patients with severe COVID-19 was not associated with significant benefits compared to the control one (standard care only) (Cao et al., 2020). In this study, $14 \%$ of the patients could not complete the treatment regimen due to adverse events. Consistently, unpublished data from the RECOVERY (Randomized Evaluation of COVid-19 thERapY) trial conducted in the United Kingdom revealed a lack of clinical benefit for lopinavir/ritonavir in patients hospitalized with COVID-19, leading to a decision to halt enrollment in this treatment arm.
According to a news release on the RECOVERY Trial website, 1,596 and 3,376 patients were randomized to lopinavir/ritonavir and standard of care alone, respectively. The 28 -day mortality was $22.1 \%$ for the lopinavir/ritonavir compared to $21.3 \%$ for the standard of care $(p=0.58)$ (Horby and Landray, 2020b). Consistently, the WHO solidarity trial announced that it will be discontinuing the lopinavir/ritonavir arm after preliminary analysis revealed little or no reduction in mortality (World Health Organization, 2020d). The data from both the RECOVERY and Solidarity trials have not been fully published to enable a complete assessment of the findings. Randomized trials are also ongoing to investigate the clinical efficacy and safety of darunavir, second-generation retroviral 
protease inhibitor in combination with a pharmacokinetic enhancer (cobicistat) in COVID-19 patients (Canadian Agency for Drugs and Technologies in Health, 2015).

\section{Favipiravir}

Favipiravir is a potent antiviral drug licensed in Japan in 2014 for novel influenza strains (Hayden and Shindo, 2019). Favipiravir selectively and potently inhibits the RNA-dependent RNA polymerase (RdRp) of RNA viruses. It undergoes phosphoribosylation and further phosphorylation intracellularly to become favipiravir ribofuranosyl-5'-triphosphate (favipiravirRTP). The active favipiravir-RTP act as a terminator of nascent RNA strand elongation by competing with purine nucleosides for RdRp binding (Sangawa et al., 2013). Other studies revealed that favipiravir induces its antiviral activity by acting as a lethal mutagen (Baranovich et al., 2013). It has shown notable efficacy against a broad-spectrum of lethal RNA viruses as the Ebola virus (Guedj et al., 2018), Lassa virus (Rosenke et al., 2018), rabies (Yamada et al., 2016), and severe fever with thrombocytopenia syndrome (Tani et al., 2018). However, in embryo-fetal developmental studies, favipiravir exposure has a risk for teratogenicity and embryotoxicity (Nagata et al., 2015). A preprint report of an open-label randomized clinical trial in Wuhan, China (ChiCTR200030254) concluded that favipiravir significantly improve the clinical recovery rate by seven days compared to umifenovir (Chen C. et al., 2020). Another openlabel, comparative, controlled study (ChiCTR2000029600) showed favipiravir exerts a more potent antiviral action against COVID-19 than lopinavir/ritonavir and with greater safety. Favipiravir showed significantly faster viral clearance and a higher improvement rate in chest imaging of treated patients compared to a control group treated with lopinavir/ritonavir (Cai et al., 2020). Several randomized trials were launched in China to test the effectiveness and efficacy of favipiravir either combined with other drugs or as a monotherapy.

\section{Ribavirin}

Ribavirin is a synthetic guanosine nucleoside that blocks viral RNA synthesis and viral mRNA capping (Sidwell et al., 1972). This prodrug, which is metabolized into nucleoside analogs, was originally tested against the respiratory syncytial virus (RSV) in pediatric patients showing only marginal clinical benefit (Ventre and Randolph, 2004). Besides RSV, ribavirin is primarily indicated for treating hepatitis $\mathrm{C}$ and viral hemorrhagic fevers (Te et al., 2007). A recent study reported that SARS-CoV-1 is sensitive to high doses of ribavirin but the effect is cell linedependent (Tan et al., 2004). Ribavirin displayed an inhibitory effect against MERS-CoV in Vero cells and LLC-MK2 cells but only at high concentrations (Falzarano et al., 2013). Although a number of laboratories have shown ribavirin to be in inhibiting SARS-CoV-1 in vitro (Koren et al., 2003; Chen et al., 2004), others failed (Cinatl et al., 2003; Barnard et al., 2004; Tan et al., 2004). Surprisingly, studies in mice revealed that ribavirin given during the first three days of infection increased SARS-CoV-1 lung viral loads and prolonged the duration of infection (Subbarao et al., 2004). In addition to the apparent lack of efficacy in most human studies, the risk of ribavirin-induced anemia along with hypoxia resulted in an increased risk of death in the treated SARS-CoV-1 patients (Barnard et al., 2006a). Thus, ribavirin may not be useful for treating SARS-CoV-1 infection because of its questionable efficacy and known toxicity. In molecular docking studies, ribavirin was predicted to tightly bind to SARS-CoV-2 RdRp (Elfiky, 2020b), but its antiviral activity has not been confirmed in vitro. The safety and efficacy of ribavirin combined with lopinavir/ritonavir and IFN- $3-1 b$ were assessed in an open-label, randomized clinical trial (NCT04276688) in Hong Kong for hospitalized adult patients with confirmed SARS-CoV-2 infection (Hung et al., 2020). The triple antiviral combination significantly reduced the time to negative nasopharyngeal swab by an average of 5 days and time to complete alleviation of symptoms by 4 days compared to the lopinavir/ritonavir (control group). However, the study lacked a placebo group and did not include critically ill patients. Also, the lack of a ribavirin and IFN- $\beta-1$ b monotherapy groups curtailed the assessment of the clinical benefit of each drug alone and warrants further investigations.

\section{Famotidine}

Famotidine is an FDA approved histamine-2 (H2) receptor antagonist indicated for suppressing gastric acid secretion (Food and Drug Administration, 1986). Computer-based target-drug screening of SARS-CoV-2 revealed that famotidine targets the $3 \mathrm{CL}^{\text {pro }}$ and may be a potential therapeutic option for the treatment of COVID-19 (Wu et al., 2020). The clinical impact of famotidine on the prognosis of COVID-19 was accidentally noticed; Janowitz et al demonstrated that a group of 10 SARS-CoV-2-infected patients who received high famotidine doses $(240 \mathrm{mg}$ in three divided doses for a median of 11 days) showed significant improvement in symptoms within 24 h of drug administration (Janowitz et al., 2020). Furthermore, a retrospective cohort study revealed that the use of famotidine significantly decreased the mortality rate and diminished the need for mechanical ventilation (Freedberg et al., 2020). In this context, a randomized clinical trial is being conducted to study the efficacy and safety of using a high dose of intravenous famotidine in COVID-19 hospitalized patients.

\section{EIDD 2801}

EIDD-2801 is an orally bioavailable $\beta$-D-N4-hydroxycytidine (NHC)-prodrug with broad-spectrum antiviral activity (Toots et al., 2019). EIDD-2801 is metabolized in vivo into NHC (EIDD1931), a pyrimidine ribonucleoside analog (Toots et al., 2019). The metabolite is incorporated into the genome of the newly formed virions resulting in the accumulation of numerous mutations that impair viral replication (Urakova et al., 2018). NHC was shown to have antiviral activity against several RNA viruses including influenza virus, RSV, chikungunya virus, Venezuelan equine encephalitis virus, Ebola virus, bovine viral diarrhea virus, and hepatitis C virus (Stuyver et al., 2003; Reynard et al., 2015; Ehteshami et al., 2017; Urakova et al., 2018; Yoon et al., 2018; Painter et al., 2019; Toots et al., 2019). In vitro studies showed that NHC has a significant inhibitory effect on SARS-CoV-1 at EC90 of $6 \mu \mathrm{M}$ in Vero 76 cells (Barnard et al., 2004). Also, the drug was shown to have a potent antiviral 
activity (IC50 of $35 \mathrm{nM}$ ) against HCoV-NL63 (Pyrc et al., 2006). NHC also efficiently inhibits murine hepatitis virus (a group 2 $\mathrm{CoV}$ ) and MERS-CoV infections in vitro and results in the accumulation of transition mutations with a genetic barrier to resistance (Agostini et al., 2019). Recently, NHC was shown to successfully suppress SARS-CoV-2 in vitro with an IC50 of 0.3 $\mu \mathrm{M}$ (Sheahan et al., 2020b). It also exhibited broad-spectrum antiviral activity against SARS-CoV-1, MERS-CoV, and a related bat-CoV in vitro (Sheahan et al., 2020b). Moreover, prophylactic and therapeutic treatment with EIDD-2801 enhanced pulmonary function and significantly decreased viral titers in the lungs of SARS- and MERS-CoV-infected mice (Sheahan et al., 2020b). The efficacy of EIDD 2801 is being investigated in randomized clinical trials but no results have been published yet.

\section{Oseltamivir}

Oseltamivir is an antiviral drug approved for treatment or prophylaxis for both seasonal and pandemic influenza infections caused by influenza A and B viruses (Smith et al., 2011). It blocks the release of influenza progeny viruses and hence restrains the spread of influenza infection in the respiratory tract (Moscona, 2005).

CoVs do not possess a functional homologue to influenza virus neuraminidase (the target of oseltamivir) neuraminidase making it unlikely for oseltamivir to be effective against SARSCoV-2 (McCreary and Pogue, 2020). Oseltamivir was empirically used with other antivirals to treat patients infected with SARS-CoV-1 but was not shown to be effective (Drosten et al., 2003; Hsu et al., 2003; Nicholls et al., 2003; Poutanen et al., 2003; Sung et al., 2004). Similarly, no inhibitory effect was observed when oseltamivir was tested against SARS-CoV-1 in vitro (Tan et al., 2004). In addition, oseltamivir treatment did not induce any improvement in hospitalized patients with MERSCoV (Al-Tawfiq et al., 2014). During the SARS-CoV-2 pandemic in Wuhan, oseltamivir was frequently used likely because of the concern of influenza and not as targeted therapy for SARS-CoV2. The drug was empirically used either with or without antibiotics and corticosteroids (Ding et al., 2020; Huang et al., 2020; Wang D. et al., 2020) and was also given to patients diagnosed with both SARS-CoV-2 and influenza virus (Ding et al., 2020). As of yet, there is no in vitro or in vivo evidence of oseltamivir efficacy or activity against SARS-CoV-2. Therefore, the rationale behind the ongoing clinical trials is not clear.

\section{Others}

A number of other virus direct-acting antivirals are being considered for the treatment of COVID-19 despite the lack of data supporting their antiviral activity against SARS-CoV-2. Penciclovir is a synthetic acyclic guanine derivative that inhibits DNA polymerase and is used for the treatment of herpes simplex infections in including HSV-1 and -2 (Earnshaw et al., 1992; Razonable, 2011; Mondal, 2016). In silico, penciclovir seems to interact with the nonstructural protein 12 (nsp12) that possesses the RdRp activity (Dey et al., 2020); yet, in vitro studies demonstrated poor antiviral activities against SARS-CoV-2 with EC50 of $95.96 \mu \mathrm{M}$ (Dhama et al., 2020; Wang M. et al., 2020). Sofosbuvir, a hepatitis C RdRp inhibitor, was predicted in silico to tightly bind SARS-CoV-1 and -2 RdRps (Noell et al., 2015; Elfiky, 2020a; Elfiky, 2020b). Azvudine (FNC) is a reverse-transcriptase inhibitor (NRTIs) that possess antiviral activity against HIV and hepatitis B viruses (Wang et al., 2011; Zhou et al., 2012). Despite the lack of any pre-clinical efficacy data and the absence of the drug target in SARS-CoV-2, clinical trials are underway in China to evaluate its effectiveness for moderate to severe COVID-19 pneumonia. Triazavirin, a guanine nucleotide analog, is currently being assessed in a multicenter randomized clinical trial despite that available data is limited to its antiviral activity against influenza viruses (Kiselev et al., 2012; Shvetsov et al., 2018).

Another interesting approach that has been proposed for COVID-19 treatment is the use of decoy ACE2 molecules to block SARS-CoV-2 from binding to their target cells. A clinicalgrade human recombinant soluble ACE2 (hrsACE2) showed a significant inhibitory effect of viral growth during the early stages of SARS-CoV-2 infection in Vero E6 cells, human blood vessel organoids, and human kidney organoids expressing ACE-2 receptor (Monteil et al., 2020). However, this approach has not been tested in animal models. The safety and tolerability of APN01 have been demonstrated in phase II trials including healthy volunteers and patients with pulmonary arterial hypertension, acute lung injury, and ALI/ARDS. A phase II randomized clinical trial of hrsACE2 (APN01) has been launched and examined for lung disease during the initial stages of SARS-CoV-2 infection (Harrison, 2020b).

\section{Host Targeting Agents \\ Azithromycin}

Azithromycin (AZM) is an FDA approved broad-spectrum macrolide antibiotic. (Fohner et al., 2017). Besides its antibacterial activity, AZM appears to possess a broad antiviral capacity. In vitro studies revealed that AZM inhibits the replication of the Zika virus by targeting a late stage of its lifecycle (Bosseboeuf et al., 2018; Li et al., 2019). AZM also showed anti-rhinovirus activity in vitro through stimulating the interferon pathway (Gielen et al., 2010; Schögler et al., 2015). Moreover, AZM possesses antiviral activity against influenza A/ H1N1pdm09 virus by interfering with its cell entry. AZM decreased $\mathrm{A} / \mathrm{H} 1 \mathrm{~N} 1 \mathrm{pdm} 09$ virus titers in the lungs and reduced infection-induced hypothermia in mice (Tran et al., 2019). AZM was also effective against the Ebola virus in cell culture but did not show reproducible efficacy in mouse models and was not effective in guinea pig model (Madrid et al., 2015).

Before the emergence of SARS-CoV-2, AZM was not previously tested against CoVs. In vitro studies showed that hydroxychloroquine/azithromycin (HCQ/AZM) (5 $\mu \mathrm{M} / 5 \mu \mathrm{M})$ combination significantly diminished SARS-CoV-2 replication (Andreani et al., 2020). However, the used AZM dose is about 5.7 times higher than the therapeutically achieved plasma concentration (Food and Drug Administration, 2010). In France, an open-label non-randomized clinical trial was conducted on 36 COVID-19 patients and showed 100\% recovery in patients receiving $\mathrm{HCQ} / \mathrm{AZM}$ and a significant reduction in viral load in patients receiving HCQ alone. 
However, the small sample size (only 6 patients in the HCQ/ AZM arm) and the non-randomized open-label design of the trial limit its reliability (Gautret et al., 2020). Consistently, a multi-center retrospective observational study from the United States revealed that the administration of HCQ with or without AZM resulted in a significant decrease in mortality in hospitalized COVID-19 patients (Arshad et al., 2020). In contrast, Magagnoli et al. demonstrated that the use of HCQ alone or in combination with AZM has no significant reduction in the need for mechanical ventilation. Also, the administration of HCQ alone was associated with a higher mortality rate (Magagnoli et al., 2020). Several clinical trials, with or without randomization, aimed at investigating the efficacy of $\mathrm{HCQ} / \mathrm{AZM}$ combination in COVID-19 patients have been registered.

\section{Ivermectin}

Ivermectin is a broad-spectrum anthelmintic agent (González Canga et al., 2008). It binds to the glutamate-activated chloride channel in the parasites' nerve and muscle cells resulting in its hyperpolarization, paralysis, and death (Ikeda, 2003). It has a broad antiviral activity spectrum in vitro. Ivermectin was shown to inhibit the replication of influenza A viruses, Venezuelan equine encephalitis virus, dengue virus, HIV-1, flavivirus, West Nile virus, and pseudorabies virus (Mastrangelo et al., 2012; Wagstaff et al., 2012; Lundberg et al., 2013; Tay et al., 2013; Götz et al., 2016; Lv et al., 2018; Yang S. N. Y. et al., 2020). A phase III, randomized, double-blind, placebo-controlled clinical trial in Thailand revealed that a once-daily dose for three days is welltolerated and resulted in enhanced serum clearance of dengue virus non-structural (NS1) protein. (Yamasmith et al., 2018). The broad-spectrum antiviral activity of ivermectin is mainly attributed to its interaction with importin (IMP) $\alpha / \beta 1$ heterodimer having a role in nuclear import (Caly et al., 2012; Jans et al., 2019). Several studies revealed the role of IMP $\alpha / \beta 1$ in the nuclear import of SARS-CoV-1 nucleocapsid protein (Rowland et al., 2005; Timani et al., 2005; Wulan et al., 2015). Moreover, SARS-CoV-1 blocks the host's antiviral response through retaining IMP $\alpha / \beta 1$ on the rough ER/Golgi membrane, inhibiting STAT1 nuclear transport and antagonizing its antiviral activity (Frieman et al., 2007). Treating Vero cells expressing the human signaling lymphocytic activation molecule (Vero-hSLAM cells) with ivermectin $(5 \mu \mathrm{M}) 2 \mathrm{~h}$ after SARS-CoV-2 infection resulted in a 5000-fold decrease in viral RNA 48 h post-infection with an IC50 of $2 \mu \mathrm{M}$ (Caly et al., 2020). However, this concentration is about four times higher than the therapeutically achieved plasma concentration without side effects (Food and Drug Administration, 2009b), suggesting a limited antiviral activity for ivermectin in humans. Randomized clinical trials investigating the efficacy of ivermectin adjuvant to HCQ or CQ are ongoing.

\section{Nafamostat and Camostat}

Nafamostat mesylate and camostat mesylate are synthetic serine protease inhibitors approved in Japan for the treatment of pancreatitis. Camostat was shown to suppress the replication of influenza $\mathrm{A} / \mathrm{H} 1 \mathrm{~N} 1 \mathrm{pdm} 09$ and $\mathrm{A} / \mathrm{H} 3 \mathrm{~N} 2$ viruses in the primary human tracheal epithelial (HTE) cells. It also reduced the concentrations of the cytokines IL-6 and TNF-alpha in primary cultures (Yamaya et al., 2015). In vitro studies revealed that nafamostat possesses antiviral activities against epidemic and zoonotic CoVs including MERS-CoV (Yamamoto et al., 2016). The anti-MERS-CoV activity is achieved through inhibition of the host protease (TMPRSS2) required for fusion-activation of the virus (Gierer et al., 2013). Consistently, Zhou et al. demonstrated that camostat displayed antiviral activity in a pathogenic animal model for SARS-CoV-1 infection by inhibiting the enzymatic activity of TMPRSS2 and other cell-surface proteases involved in $\mathrm{CoV}$ activation (Zhou et al., 2015). Recently, camostat was shown to suppress SARS-CoV-2 S protein-initiated fusion in 293FT cells ectopically expressing ACE2 and TMPRSS2 (Hoffmann et al., 2020). Currently, the safety and efficacy of camostat are being assessed in randomized clinical trials. Moreover, other randomized studies comparing the efficacy of camostat-HCQ combination to HCQ-AZM combination or monotherapy are being conducted.

\section{Teicoplanin}

Teicoplanin, formerly known as teichomycin A, is a natural glycopeptide antibiotic produced from the actinomycete Actinoplanes teichomyceticusteino and commonly used for the treatment of gram-positive infections (Parenti et al., 1978; Borghi et al., 1984; Svetitsky et al., 2009). The drug is not approved by the FDA but is commercially available in Europe, Asia, and South America (Parente and Laplante, 2017). The bactericidal activity of the drug is mediated mainly by the inhibition of peptidoglycan synthesis of the bacterial cell wall (Corti et al., 1985; Murray et al., 2015). In addition to its antibacterial activity, teicoplanin is a viral entry inhibitor with a broad-spectrum of activity. Teicoplanin and/or teicoplanin derivatives were shown to have in vitro antiviral activities against several viruses such as feline infectious peritonitis virus (FIPV), SARS-CoV-1, HIV-1, influenza virus, flaviviruses, including Ebola virus, and RSV (Balzarini et al., 2006; Preobrazhenskaya and Olsufyeva, 2006; Burghgraeve et al., 2012; Bakai-Bereczki et al., 2014; Wang Y. et al., 2016). Teicoplanin aglycon derivatives were reported to suppress the intracellular replication of the hepatitis $C$ virus in vitro (Obeid et al., 2011). Moreover, teicoplanin therapy significantly reduced the viral load in a patient with chronic hepatitis C (Maieron and Kerschner, 2012). Zou et al. reported that teicoplanin suppresses the entry of the Ebola virus, SARSCoV-1, and MERS-CoV by blocking the activity of cathepsin L in the late endosome/lysosome (Zhou et al., 2016). Inhibition of the cysteine protease, cathepsin L, prevents the cleavage and the subsequent activation of the S glycoprotein of CoVs, a key step required for virus fusion and release of the viral genome (Zhou et al., 2016; Baron et al., 2020). It was recently shown that teicoplanin efficiently restricts the entry of SARS-CoV-2 pseudovirus with an IC50 of $1.66 \mu \mathrm{M}$, which is less than the usual trough plasma drug concentration $(7-8 \mu \mathrm{M}$ ) (Zhang et al., 2020a). Molecular docking studies show an interaction between teicoplanin and SARS-CoV-2 3CL ${ }^{\text {Pro }}$ (Azam, 2020). Further preclinical investigations are needed to assess the inhibitory effect of teicoplanin against wildtype SARS-CoV-2. 


\section{Nitazoxanide}

Nitazoxanide is a thiazolide derivative that possesses a broadspectrum antiviral and anti-parasitic activity (White, 2004; Rossignol, 2014). It is FDA-approved for the treatment of parasitic infections caused by Cryptosporidium parvum and Giardia lamblia (Fox and Saravolatz, 2005). Nitazoxanide has broad antiviral activity against several DNA and RNA viruses. In vitro studies confirmed its effectiveness against RSV (Nichols et al., 2008), HIV (Rossignol, 2014), Japanese encephalitis virus (Shi et al., 2014), hepatitis B and C viruses (Korba et al., 2008), rotavirus (La Frazia et al., 2013), and Ebola virus (Jasenosky et al., 2019). Also, nitazoxanide is effective against multiple anti-influenza virus types/ subtypes. It inhibits hemagglutinin maturation and incorporation in the cell surface by blocking its post-translational glycosylation (Rossignol, 2014). Previous in vitro studies showed that it has robust antiviral activity against murine $\mathrm{CoV}$ and MERS-CoV by blocking viral entry and replication (Cao et al., 2015; Rossignol, 2016). The drug inhibited SARS-CoV-2 replication in Vero E6 cells at a low concentration (EC50 $=2.12 \mu \mathrm{M})$ (Wang M. et al., 2020) and this concentration is three times lower than the common therapeutically achieved one (Fox and Saravolatz, 2005). In addition, to its host-acting antiviral activity, nitazoxanide inhibits the production of pro-inflammatory cytokines, including interleukin 6 (IL-6), a property that can be very beneficial in COVID-19 treatment (Russell B. et al., 2020). Clinical trials, including randomized ones, investigating the efficacy and safety of nitazoxanide are ongoing.

\section{Drugs with Mixed Modes of Action}

\section{Umifenovir}

Umifenovir (commonly known as arbidol) is an antiviral medication licensed in Russia and China for prophylaxis and treatment of influenza virus infections. It has shown a broadspectrum antiviral activity in vitro and in vivo against a wide range of enveloped or non-enveloped RNA or DNA viruses, including members of the families Orthomyxoviridae, Paramyxoviridae, Flaviviridae, Filoviridae, Herpesviridae Picornaviridae, and Coronaviridae (Leneva et al., 2002; Pécheur et al., 2016; Haviernik et al., 2018; Herod et al., 2019). Umifenovir has been shown to possess both direct-acting and host-targeting antiviral activities through a range of proposed modes of action including interacting with host membrane lipids and proteins and viral glycoproteins, elevating the endosomal $\mathrm{pH}$, and interfering with intracellular trafficking (reviewed in details in (Blaising et al., 2014)).

Umifenovir was shown to inhibit SARS-CoV-1 infection in GMK-AH-1 cells (Khamitov et al., 2008). It also efficiently inhibited SARS-CoV-2 infection in vitro at a low concentration $(4.11 \mu \mathrm{M})$ suggesting that it could be effective in the treatment of COVID-19 (Wang X. et al., 2020). A retrospective case-control study was conducted in Wuhan, China, found that umifenovir was more effective than oseltamivir as post-exposure prophylaxis among healthcare workers and family members with high exposure risk to COVID-19. The study had some limitations, including the use of oseltamivir as a comparator drug (Zhang et al., 2020c). Wang et al. reported clinical improvement in three COVID-19 patients treated with a combination of lopinavir/ ritonavir, umifenovir, and traditional Chinese Medicine (Wang et al., 2020a). Deng et al. showed in a retrospective observational study that 16 COVID-19 patients treated with umifenovir plus lopinavir/ritonavir combination had more favorable viral clearance and chest CT findings compared to lopinavir/ ritonavir monotherapy (Deng et al., 2020). A retrospective study demonstrated that early administration of umifenovir or umifenovir in combination IFN significantly shortened the duration of viral shedding in COVID-19 patients (Zhou Y. et al., 2020). Furthermore, a limited retrospective cohort study reported that umifenovir tends to improve the discharging rate and reduce mortality rate (Wang et al., 2020b). Another retrospective study on family members and healthcare workers showed that umifenovir could act as protective post-exposure prophylaxis of COVID-19 transmission (Zhang et al., 2020b). Reconcilable results were observed in a retrospective case-control study that found a preventative role of prophylactic umifenovir use in lowering the incidence of SARS-CoV-2 infection of health professionals but no correlation to hospitalization rate was found (Yang C. et al., 2020).

In contrast, a clinical study (NCT04252885) involving 44 mild-to-moderate COVID-19 patients, found no clinical benefit for umifenovir or lopinavir/ritonavir monotherapy compared to the control standard-of-care group (Li Y. et al., 2020). Similarly, another retrospective study indicated that umifenovir treatment in mild-to-moderate COVID-19 patients was neither with improvement of clinical symptoms nor altered the duration to viral clearance (Jun et al., 2020). Despite the lack of evidence supporting its efficacy, umifenovir was added to the latest version of the Guidelines for the Prevention, Diagnosis, and Treatment of Novel Coronavirus-induced Pneumonia issued by the National Health Commission (NHC) China for tentative treatment of COVID-19 (Dong et al., 2020).

\section{Chloroquine Phosphate and Hydroxychloroquine}

Chloroquine phosphate (CQ), a 4-aminoquinoline compound, is approved for the treatment of malaria and extraintestinal amebiasis (Food and Drug Administration, 2009a). It is also being used as an off-label anti-inflammatory agent for the treatment of rheumatoid arthritis and lupus erythematosus owing to its immunomodulatory properties (National Institute of Diabetes and Digestive and Kidney Diseases, 2012). Hydroxychloroquine (HCQ), a chloroquine phosphate derivative, is also an FDA-approved antimalarial and immunomodulatory agent. It is prescribed for the prophylaxis and treatment of uncomplicated chloroquinesensitive malaria, treatment of chronic discoid lupus erythematosus, systemic lupus erythematosus, and acute and chronic rheumatoid arthritis in adults (Food and Drug Administration, 2018).

CQ and HCQ exert their antimalarial activity by accumulating in the parasites' acidic food vacuoles and inhibiting the transformation of the toxic heme into hemozoin biocrystal that is needed for survival (Parhizgar and Tahghighi, 2017; Food and Drug Administration, 2018). Their anti-rheumatic activity is achieved by hindering the auto-immune response. CQ and HCQ are lysosomotropic agents that gain access into the lysosomes and increase their $\mathrm{pH}$ leading to the inhibition of acidic proteases. This 
process interferes with the antigen processing, dimerization of the major histocompatibility complex (MHC) class II, antigen presentation, and the stimulation of CD4+ T cells. Furthermore, they diminish the production of pro-inflammatory cytokines by interfering with Toll-like receptor (TLR) signaling (in the endosome) and inhibiting the nucleic acid sensor cyclic GMPAMP (cGAMP) synthase (in the cytosol) (Savarino et al., 2003).

Besides their antimalarial and immune-modulatory effects, CQ and HCQ possess antiviral activities. Upon uptake, HCQ/CQ get trapped inside endosomes, lysosomes and Golgi vesicles (mammals) increasing its PH (Al-Bari, 2015). In this context, CQ and HCQ may be potential treatment options for viruses depending on low endosomal $\mathrm{pH}$ for cellular internalization (AlBari, 2017). They possess promising activity against human HIV1. However, its exact mechanism of action is still not fully understood. Still, it is likely attributed to the impairment of the post-translational processing of HIV glycoproteins by increasing the $\mathrm{pH}$ of the trans-Golgi network (Tsai et al., 1990; Romanelli et al., 2004; Paton et al., 2012). Moreover, CQ inhibits the replication of human influenza A viruses (H1N1 and H3N2) in vitro (Ooi et al., 2006) but not in vivo (Vigerust and McCullers, 2007). CQ was also tested against dengue virus; in vitro studies revealed a decrease in virus titer (Farias et al., 2013), and in vivo studies using nonhuman primates (monkeys) showed improvement in symptoms upon treatment with CQ (Farias et al., 2015). However, clinical studies showed that CQ did not reduce the duration of dengue infection and time to recovery, despite improvement in the quality of life of patients (Tricou et al., 2010; Borges et al., 2013). Wang et al. reported that HCQ inhibits dengue virus by the activation of reactive oxygen species and a mitochondrial antiviral signaling proteinmediated host interferon type I antiviral pathway (Wang et al., 2015). CQ also possesses antiviral efficacy against the Zika virus in different cell lines (Delvecchio et al., 2016) and mice models (Li et al., 2017; Shiryaev et al., 2017). It blocks the release of the Zika virus from the endosome and inhibits virus-induced autophagy and autophagy-dependent replication (Zhang et al., 2019). CQ was also shown to inhibit the Japanese encephalitis virus by restricting its $\mathrm{pH}$-dependent internalization in rat neuroblastoma cells (Zhu et al., 2012).

The efficacy of CQ and HQC against SARS-CoV-1, MERS$\mathrm{CoV}$, and other human CoVs has been also described (Keyaerts et al., 2004; Vincent et al., 2005; Kono et al., 2008; de Wilde et al., 2014). CQ possesses potent in vitro antiviral activity against SARS-CoV-1 when added pre- or post-infection. This antiviral activity was partially attributed to the impairment of ACE2 terminal glycosylation that is needed for SARS-CoV-1 binding (Vincent et al., 2005). CQ-induced increase in endosomal pH inhibits the $\mathrm{pH}$-dependent SARS-CoV-1 internalization (Yang et al., 2004). CQ increased the survival of newborn mice infected with HCoV-OC43 (Keyaerts et al., 2009). However, it did not result in a significant reduction in SARS-CoV-1 lung virus titer in BALB/c mice (Barnard et al., 2006b).

The antiviral activity of CQ and HCQ against SARS-CoV-2 has also been reported. In vitro studies showed that CQ effectively inhibits SARS-CoV-2 in Vero E6 cells $($ EC50 $=1.13$ $\mu \mathrm{M}$ ) (Wang M. et al., 2020). Liu et al. demonstrated that CQ has a lower EC50 compared to HCQ (Liu J. et al., 2020). In contrast, Yao et al. demonstrated that HCQ $(\mathrm{EC} 50=0.72 \mu \mathrm{M})$ exhibits a stronger anti-SARS-CoV-2 activity than CQ $($ EC50 $=5.74 \mu \mathrm{M})$ (Yao et al., 2020). The efficacy of HCQ against SARS-CoV-2 at plasma concentrations that can be obtained using clinically approved doses was tested, but unfortunately, HCQ (1 or $2 \mu \mathrm{g} /$ $\mathrm{mL}$ ) did not result in any significant reduction in viral loads in Vero E6 cells (Kang et al., 2020). Preliminary data from more than 100 patients recruited in clinical trials in China demonstrated that CQ was superior to control in ameliorating the symptoms, diminishing the duration of the disease, and achieving total recovery in patients with COVID-19-associated pneumonia (Gao et al., 2020). However, the full results of these studies have not been released yet. Arshad et al. reported in a multi-center retrospective observational study that HCQ treatment resulted in a reduction of COVID-19 mortality compared to no treatment (Arshad et al., 2020). On the contrary, HCQ administration was not associated with significant reductions in the risk of intubation and deaths in two observational studies including COVID-19 hospitalized patients in the United States (Geleris et al., 2020, 19) (Magagnoli et al., 2020). Compelling evidence came from the RECOVERY and Solidarity randomized clinical trials, which recently announced stopping the HCQ arm due to lack of clinical benefit revealed in the interim analysis (Horby and Landray, 2020a; World Health Organization, 2020d). In the RECOVERY trial, 1542 patients randomly received HCQ and compared with 3132 patients who received standard of care alone. The 28-day mortality for the HCQ was $25.7 \%$ compared to $23.5 \%$ in the control group (hazard ratio 1.11 [0.98-1.26]; $\mathrm{p}=0.10$ ). Full data from both studies have not been disclosed yet. In acute viral infections administering the antiviral drug early during infection might be of greater clinical benefit. Nonetheless, two randomized clinical trials showed that early administration of HCQ for adult outpatients with mild COVID19 did not have clinical benefit in terms of clinical recovery and reducing disease severity or viral load (Mitjà et al., 2020; Skipper et al., 2020). Moreover, HCW was not effective in preventing laboratory-confirmed or clinically suspected COVID-19 compared to placebo (Boulware et al., 2020). In conclusion, CQ or HCQ are evidently of no clinical benefit in COVID-19 patients. Moreover, their use for patients with severe COVID-19 was associated with concerns regarding the elongation of the QT interval requiring careful monitoring of the treated patients (Borba et al., 2020; Chorin et al., 2020).

\section{Disease Modulating Adjunctive Therapy Immunomodulatory Agents Fingolimod}

Fingolimod (FTY720) is a sphingosine-1-phosphate (S1P) receptor modulator (Blanc et al., 2015). It induces immunomodulatory properties that trap naïve and memory $\mathrm{T}$ cells in lymph nodes resulting in a reduced peripheral circulation (Pfender et al., 2015). It is licensed for the treatment of patients with relapsing multiple sclerosis. (Blanc et al., 2015). In vitro and 
in vivo studies suggested that fingolimod can be utilized as a treatment against HIV remission by limiting the viral persistence and its T cells reservoir (Geffin et al., 2017; Pino et al., 2019). The immunomodulatory properties of fingolimod can be useful in suppressing the hyperinflammatory response in severe COVID19 patients. There were recent reports of COVID-19 patients under fingolimod treatment for multiple sclerosis (Foerch et al., 2020; Merad and Martin, 2020). One patient (a 42-year-old female) had a favorable outcome, while the other (a 57-year old female) required ICU admission and ventilation. Therefore, the timing of fingolimod administration might be critical as its immunosuppressive properties might enhance virus replication when administered early during infection. It might be also important to test patients for varicella-zoster virus infections as there have been reports of relapse in patients treated with fingolimod (Pfender et al., 2015; Manni et al., 2017; RedelmanSidi et al., 2018). Two clinical trials, including one randomized, were registered to test the effectiveness of fingolimod against COVID-19.

\section{Thymosin $\alpha 1$}

Thymosin $\alpha 1$ is a naturally occurring 28-amino acid peptide with immunomodulatory properties that can trigger lymphocyte maturation, enhance $\mathrm{T}$ cell activation, and improve the immune response (Low and Goldstein, 1984). It has an antineoplastic activity and is used as an anticancer treatment (Billich, 2002; Maio et al., 2010). It was used as an adjuvant with influenza (H1N1pdm09 and H9N2) vaccines to boost the immune response and the vaccine efficacy (Carraro et al., 2012; Wang C. et al., 2016). It is also approved in some countries for the treatment of chronic viral infections such as hepatitis B and C (Andreone et al., 2001; Kullavanuaya et al., 2001; Iino et al., 2005). Moreover, thymosin $\alpha 1$ successfully enhanced cellular immunity against cytomegalovirus disease and HIV (Chadwick et al., 2003; Ji et al., 2007). The drug was patented for the treatment of SARS-CoV-1 infection (Rudolph and Tuthill, 2010). A recent retrospective study evaluated the clinical efficacy and benefit of thymosin $\alpha 1$ for severe COVID-19 patients; thymosin treatment was associated with a significant reduction in mortality. Besides, thymosin $\alpha 1$ boosts the immune functions in patients with severe lymphocytopenia via promoting thymus output (Liu Y. et al., 2020). It is currently used in three COVID-19 clinical trials in China with various combinations including PD-1 blocking antibody, recombinant human IFN- $\alpha-1 b$, or protease inhibitors (Harrison, 2020a).

\section{Tocilizumab}

Tocilizumab is a recombinant anti-human interleukin-6 receptor (IL-6R) monoclonal antibody indicated for the treatment of rheumatoid arthritis (RA), juvenile idiopathic arthritis (JIA), and giant cell arteritis (Woodrick and Ruderman, 2011; Stone et al., 2017). It is also approved for cytokine release syndrome, a side-effect of CAR-T cell therapies (Food and Drug Administration, 2019). IL-6 is crucial for the host to mount an immune response against a wide range of viruses including influenza, vaccinia virus, Andes virus, vesicular stomatitis virus, etc. (Angulo et al., 2017; Velazquez-Salinas et al., 2019).
Early studies on SARS-CoV-1 and MERS-CoV infections demonstrated that an increase in serum pro-inflammatory cytokines such as IL-1B, IL-6, and IL-12, among others, was associated with extensive lung damage in patients (Wong et al., 2004; Huang et al., 2005; Mahallawi et al., 2018). With SARS$\mathrm{CoV}-2$, respiratory failure from acute respiratory distress syndrome (ARDS) is the leading cause of mortality, with IL-6 levels being a significant predictor (Ruan et al., 2020). The cytokine profile observed in patients with severe COVID-19 is suggestive of cytokine storm, characterized by fatal hypercytokinemia and multi-organ failure (Huang et al., 2020). Even though hyper-inflammation exacerbates lung injury, corticosteroids are not recommended for COVID-19 routine treatment and might worsen respiratory symptoms (Russell C. D. et al., 2020). However, in cases where patients with severe COVID-19 present with "cytokine storm," immunosuppression with tocilizumab has been proposed as a potential treatment (Mehta et al., 2020). T cell exhaustion was detected in $75 \%$ of non-ICU COVID-19 patients and $90 \%$ of ICU patients. The reduction in $\mathrm{T}$ cell functionality was attributed to the hypercytokinemia, suggesting a potential role for tocilizumab in restoring $\mathrm{T}$ cell counts in COVID-19 patients (Diao et al., 2020). A retrospective assessment of tocilizumab treatment found that it can ameliorate and reduce inflammatory biomarker levels supporting its effectiveness in relieving cytokine storms (Luo et al., 2020). A small observational study of patients with severe and critical COVID19 did not report any mortality upon tocilizumab treatment and showed improvement in patients' symptoms, hypoxygenemia, and CT lung (Xu et al., 2020). Retrospective analysis of 15 moderate-to-critically ill patients found that tocilizumab treatment was associated with a reduction in IL-6 and CRP levels (an inflammatory activity marker) compared to before initiating treatment (Guaraldi et al., 2020). Another retrospective cohort study found that tocilizumab administration significantly shortened the duration of vasopressor support in hypoxic COVID-19 patients compared to the no tocilizumab control group ( 2 vs. 5 days, respectively; $p=0.039$ ). The time to clinical improvement and invasive ventilation was shorter, albeit not significantly, in the tocilizumab group compared to the control group (Kewan et al., 2020). Interestingly, a COVID19 patient with multiple myeloma was successfully treated with tocilizumab (Zhang X. et al., 2020).

In late April, a preliminary report of phase II randomized trial on tocilizumab (NCT04331808) described no clear benefit and improvement of clinical outcomes in patients with moderate to severe pneumonia associated with COVID19, yet it showed minor positive trends with critical COVID-19 cases (Regeneron Pharmaceuticals. Inc, 2020). However, the phase III trial was shut down as tocilizumab failed to show clinical benefit in critically ill, mechanically ventilated patients. Thus, further research and evidence on tocilizumab effectiveness and side effects are needed before issuing a treatment recommendation. Tocilizumab is currently being investigated in several trials, including randomized ones, in patients with COVID-19 pneumonia and elevated IL-6. 


\section{Bevacizumab}

Bevacizumab, a humanized monoclonal antibody against the angiogenic vascular endothelial growth factor (VEGF), is being investigated for the treatment of acute lung injury in COVID-19. The literature is conflicting regarding the role of VEGF in the normal lung. Some studies have suggested a protective role for VEGF on the alveolar epithelium following injury (Medford and Millar, 2006). This is supported by the fact that VEGF is found in substantial quantities in the normal lung. Conversely, other studies have proposed that it may participate in the development of non-cardiogenic pulmonary edema, worsening lung injury. This is supported by experiments showing that the administration of soluble VEGF receptors reduces the extent of pulmonary edema (Kaner et al., 2000). A unifying model is that VEGF functions in an autocrine fashion to repair and regenerate the alveolar epithelial surface, yet contributes to the development of pulmonary edema if the alveolar-capillary membrane is disrupted, as is the case during acute lung injury (Medford and Millar, 2006). These findings triggered interest in the potential therapeutic role for bevacizumab in ARDS, a leading cause of COVID-19 mortality. Retrospective studies have identified elevated levels of VEGF in the blood of COVID-19 patients (Huang et al., 2020). Rising VEGF levels were hypothesized to be due to hypoxia and severe inflammation, and thought to be one of the causes of respiratory failure in COVID-19 (Viveiros Rosa and Santos, 2020). Clinical trials, including randomized ones, are underway to test bevacizumab as a treatment for ARDS in COVID-19 patients.

\section{Colchicine}

Colchicine is an FDA-approved drug for the prophylaxis and treatment of gout flares and the treatment of Familial Mediterranean Fever (FMF). It has other off-label uses, including the treatment of Behcet's syndrome, an autoimmune vasculitis. The exact mechanism of action of colchicine is not well understood. Its primary mode of action is thought to be tubulin disruption, which leads to the downregulation of multiple inflammatory pathways (Leung et al., 2015). By preventing microtubule assembly, colchicine disrupts the inflammasome complex and consequently blocks activation of IL-1. It also inhibits microtubule-dependent chemotaxis of neutrophils, generation of leukotrienes and cytokines, phagocytosis, and the (TNF- $\alpha$ )-induced NF- $\kappa B$ pathway. In addition, it has anti-fibrotic effects (Dalbeth et al., 2014; Leung et al., 2015). These properties have led researchers to suggest a potential role for colchicine in the treatment of COVID-19 pneumonia, especially with regards to attenuating the cytokine storm and associated pulmonary edema. A randomized, open-label study found that hospitalized COVID-19 patients in the colchicine group had significantly improved time to clinical deterioration compared to those receiving standard care. Nevertheless, there were no significant differences between the groups when examining cardiac and inflammatory biomarkers (Deftereos et al., 2020). The study was underpowered with limited sample size, but it supports the potential therapeutic benefit of colchicine in COVID-19 patients. Several randomized clinical trials are ongoing to study the safety and efficacy of colchicine to reduce lung complications related to COVID-19.

\section{Corticosteroids \\ Methylprednisolone}

Methylprednisolone is an FDA-approved immunosuppressive and anti-inflammatory agent. It is indicated for use as a replacement therapy or systemic symptomatic treatment (Yasir et al., 2020). Owing to its anti-inflammatory benefits, at low doses, corticosteroids including methylprednisolone have been widely tested for a variety of viral infections. However, its clinical benefits remain controversial.

In RSV-infected children, no clinical benefits were achieved with the use of corticosteroids (Corneli et al., 2007). Moreover, the use of corticosteroids appeared to be harmful in viral hepatitis and cerebral malaria (McGee and Hirschmann, 2008). A meta-analysis of 6548 patients from ten studies comparing the effects of corticosteroids, including methylprednisolone, to placebo in patients with influenza-associated pneumonia revealed that corticosteroids were associated with increased mortality (Ni et al., 2019).

An uncontrolled, non-randomized study of high-dose methylprednisolone treatment found that the majority (89\%) of SARS patients recovered from progressive lung disease oneweek post-illness (Sung et al., 2004). However, a systematic review of corticosteroids use in SARS revealed that 25 studies were inconclusive, while four revealed evidence of possible harm including decreased virus clearance and drug-induced complications (Stockman et al., 2006). Corticosteroids were commonly utilized in the treatment of MERS-CoV-infected patients but its effect on clinical outcome was controversial. Thus, a multicenter study was conducted to investigate the effectiveness of corticosteroid therapy on MERS-associated mortality and viral clearance. This study showed that corticosteroid therapy did not improve survival and was associated with a delay in MERS-CoV clearance (Arabi et al., 2017). Although clinical evidence from other viral infections is not supportive of clinical benefit, several clinical trials including a randomized one, are underway to assess the safety and efficacy of methylprednisolone in COVID-19.

\section{Dexamethasone}

Dexamethasone is a steroid that has been indicated to treat a wide range of conditions including asthma, allergies, and autoimmune conditions such as lupus and rheumatoid arthritis (Shrestha et al., 2019; Elkharwili et al., 2020; Wang Q. et al., 2020). It has been used for its anti-inflammatory and immunosuppressant effects. While not a COVID-19 cure, dexamethasone has emerged with strong evidence of improving COVID-19 survival and mortality in severely ill patients. Preliminary results released from a randomized, controlled, Phase II/III clinical trial found that dexamethasone significantly reduced deaths among those with severe COVID-19 illnesses. Of the total 11,320 patients included in the RECOVERY trial, 2104 patients were randomized to receive dexamethasone for 10 days and 4321 were randomized to usual care only. The remainder were randomized to one of the other treatment arms. 
Compared to standard care, dexamethasone was found to significantly reduce deaths by one-third ( $29.3 \%$ vs. $41.4 \%$; rate ratio, 0.64 [0.51 to 0.81$]$ ) among ventilated patients and by onefifth ( $23.3 \%$ vs. $26.2 \%$; rate ratio, 0.82 [0.72 to 0.94$])$ in patients who require oxygen only. Although the drug was successful in treating many seriously ill patients, there was no benefit in administering it to those with milder cases who did not require respiratory support at randomization (The RECOVERY Collaborative Group, 2020). Additional 14 clinical trials are planned to investigate the efficacy of dexamethasone against COVID-19 with eight trials expected to complete in 2020.

\section{Convalescent Plasma}

The use of antibodies from recovered COVID-19 patients is currently considered to treat active cases. Antibodies provide passive immunity by viral neutralization or possibly by inducing antibody-dependent cellular cytotoxicity mechanism (Casadevall and Pirofski, 2020). A fast, though not very scalable, way to provide passive immunization is by using convalescent plasma from recovered COVID-19 patients. The use of convalescent sera has shown promise in various infectious diseases including measles, poliomyelitis, mumps, and influenza (Casadevall and Pirofski, 2020). Convalescent plasma therapy was also evaluated during the SARS-CoV-1 outbreak in 2003, resulting in a significantly higher 22-day discharge rate among treated patients compared to controls (Cheng et al., 2005). Nonetheless, other studies on the use of convalescent plasma to treat SARS patients were inconclusive (Stockman et al., 2006). During the MERS outbreak in South Korea, two of three MERS patients with respiratory failure who received convalescent plasma infusion demonstrated neutralizing antibody activity (Ko et al., 2018).

Based on these previous experiences, the FDA facilitated access to COVID-19 convalescent plasma for compassionate use in patients with immediately-life threatening COVID-19 under emergency use authorization (EUA) (Food and Drug Administration, 2020). A study from the USA reported encouraging preliminary results on the safety and efficacy of convalescent plasma therapy in patients with life-threatening COVID-19 disease. At least one-point clinical improvement was demonstrated in $36 \%$ of patients on day 7 , and $76 \%$ had improved or been discharged by day 14 . No adverse events were observed indicating convalescent plasma is a safe treatment option for severely ill COVID-19 patients (Salazar et al., 2020). These findings were consistent with another study of 5000 patients treated with convalescent plasma. The incidence of serious adverse events was $<1 \%$ during the first four postinfusion and the overall seven-day incidence of mortality was 14.9\% (Joyner et al., 2020). Liu et al. assessed the outcomes of convalescent plasma in 39 severely ill COVID-19 patients. Compared to matched control, convalescent plasma administration significantly improved survival rate in nonintubated patients but not in intubated ones (Liu S. et al., 2020). Data from an open-label, multicenter, randomized clinical trial of 103 COVID-19 patients with a severe or lifethreatening disease show clinical improvement within 28 days in $52 \%(\mathrm{n}=27)$ of patients who received convalescent plasma compared to $43 \%(n=22)$ of patients in the control group.
However, there was no difference in the 28 -day mortality rate between both groups. The negative viral PCR conversion rate was higher $(87.2 \%)$ in the treatment group than the standard care group (37.5\%) (Li L. et al., 2020). Unfortunately, the study was terminated early as the outbreak was waning in China. A number of clinical trials including randomized ones have already been launched and others were submitted to the FDA to test the effect of convalescent plasma as a treatment for COVID-19.

\section{CONCLUSION}

The COVID-19 pandemic constitutes an unprecedented challenge to global public health. The first wave of the pandemic was largely mitigated thanks to worldwide lockdowns that averted millions of infections (Hsiang et al., 2020). The world is counting on the development of vaccines to effectively control the pandemic; however, while early clinical trials revealed promising results, a vaccine is unlikely to be widely available before late 2021 (Funk et al., 2020). Thus, the repurposing of existing drugs is the fastest approach to mitigate the COVID-19 burden for the near future. The rapid response to undertake clinical trials of repurposed drugs initially promised fast results; however, most of the early have been disappointing or controversial, to say the least. Several clinical trials are ongoing worldwide and some have already been concluded. These efforts have successfully proven clinical and survival benefits for remdesivir and dexamethasone in hospitalized patients with severe COVID-19. It remains important to identify drugs that can be safely used during the early stage of infection to prevent progression to severe disease and deaths.

\section{AUTHOR CONTRIBUTIONS}

$\mathrm{HZ}$ conceived the idea and supervised the writing. $\mathrm{HZ}, \mathrm{MK}$, and MA developed the review outline. MK and MA led and coordinated the drafting of the manuscript. MK, MA, GH, NS, $\mathrm{AA}, \mathrm{HA}$, and $\mathrm{SH}$ wrote the manuscript. AE critically reviewed the manuscript. All authors contributed to the article and approved the submitted version.

\section{FUNDING}

This paper was supported by an American University of Beirut, Faculty of Medicine MPP (grant number 320126) and the Lebanese National Council for Scientific Research (CNRS; grant number 103937) to $\mathrm{HZ}$.

\section{ACKNOWLEDGMENTS}

We thank BioRender.com for providing us with a free trial to create the figure. 


\section{REFERENCES}

Agostini, M. L., Andres, E. L., Sims, A. C., Graham, R. L., Sheahan, T. P., Lu, X., et al. (2018). Coronavirus Susceptibility to the Antiviral Remdesivir (GS-5734) Is Mediated by the Viral Polymerase and the Proofreading Exoribonuclease. mBio 9, e00221-8. doi: 10.1128/mBio.00221-18

Agostini, M. L., Pruijssers, A. J., Chappell, J. D., Gribble, J., Lu, X., Andres, E. L., et al. (2019). Small-Molecule Antiviral $\beta$-d-N4-Hydroxycytidine Inhibits a Proofreading-Intact Coronavirus with a High Genetic Barrier to Resistance. J. Virol. 93, e01348-19. doi: 10.1128/JVI.01348-19

Al-Bari, M. A. A. (2015). Chloroquine analogues in drug discovery: new directions of uses, mechanisms of actions and toxic manifestations from malaria to multifarious diseases. J. Antimicrob. Chemother. 70, 1608-1621. doi: 10.1093/ jac/dkv018

Al-Bari, Md. A.A. (2017). Targeting endosomal acidification by chloroquine analogs as a promising strategy for the treatment of emerging viral diseases. Pharmacol. Res. Perspect. 5, 1608-1621. doi: 10.1002/prp2.293

Al-Tawfiq, J. A., Momattin, H., Dib, J., and Memish, Z. A. (2014). Ribavirin and interferon therapy in patients infected with the Middle East respiratory syndrome coronavirus: an observational study. Int. J. Infect. Dis. 20, 42-46. doi: 10.1016/j.ijid.2013.12.003

Andreani, J., Le Bideau, M., Duflot, I., Jardot, P., Rolland, C., Boxberger, M., et al. (2020). In vitro testing of combined hydroxychloroquine and azithromycin on SARS-CoV-2 shows synergistic effect. Microb. Pathog. 145:104228. doi: 10.1016/j.micpath.2020.104228

Andreone, P., Cursaro, C., Gramenzi, A., Margotti, M., Ferri, E., Talarico, S., et al. (2001). In vitro effect of thymosin-alphal and interferon-alpha on Th1 and Th2 cytokine synthesis in patients with chronic hepatitis C. J. Viral. Hepat. 8, 194-201. doi: 10.1046/j.1365-2893.2001.00285.x

Angulo, J., Martínez-Valdebenito, C., Marco, C., Galeno, H., Villagra, E., Vera, L., et al. (2017). Serum levels of interleukin-6 are linked to the severity of the disease caused by Andes Virus. PloS Negl. Trop. Dis. 11, e0005757. doi: 10.1371/journal.pntd.0005757

Arabi, Y. M., Mandourah, Y., Al-Hameed, F., Sindi, A. A., Almekhlafi, G. A., Hussein, M. A., et al. (2017). Corticosteroid Therapy for Critically Ill Patients with Middle East Respiratory Syndrome. Am. J. Respir. Crit. Care Med. 197, 757-767. doi: 10.1164/rccm.201706-1172OC

Arshad, S., Kilgore, P., Chaudhry, Z. S., Jacobsen, G., Wang, D. D., Huitsing, K., et al. (2020). Treatment with Hydroxychloroquine, Azithromycin, and Combination in Patients Hospitalized with COVID-19. Int. J. Infect. Dis. 0, 396-403. doi: 10.1016/j.ijid.2020.06.099

Azam, F. (2020). Targeting SARS-CoV-2 Main Protease by Teicoplanin: A Mechanistic Insight by in Silico Studies. doi: 10.26434/chemrxiv.12408650.v1

Bakai-Bereczki, I., Kicsák, M., Dobray, L., Borbás, A., Batta, G., Keki, S., et al. (2014). Semisynthetic teicoplanin derivatives as new influenza virus binding inhibitors: Synthesis and antiviral studies. Bioorg. Med. Chem. Lett. 24, 32513254. doi: 10.1016/j.bmcl.2014.06.018

Balzarini, J., Keyaerts, E., Vijgen, L., Egberink, H., De Clercq, E., Van Ranst, M., et al. (2006). Inhibition of feline (FIPV) and human (SARS) coronavirus by semisynthetic derivatives of glycopeptide antibiotics. Antiviral Res. 72, 20-33. doi: $10.1016 /$ j.antiviral.2006.03.005

Baranov, P. V., Henderson, C. M., Anderson, C. B., Gesteland, R. F., Atkins, J. F., and Howard, M. T. (2005). Programmed ribosomal frameshifting in decoding the SARS-CoV genome. Virology 332, 498-510. doi: 10.1016/ j.virol.2004.11.038

Baranovich, T., Wong, S.-S., Armstrong, J., Marjuki, H., Webby, R. J., Webster, R. G., et al. (2013). T-705 (Favipiravir) Induces Lethal Mutagenesis in Influenza A H1N1 Viruses In Vitro. J. Virol. 87, 3741-3751. doi: 10.1128/JVI.02346-12

Barnard, D. L., Hubbard, V. D., Burton, J., Smee, D. F., Morrey, J. D., Otto, M. J., et al. (2004). Inhibition of Severe Acute Respiratory Syndrome-Associated Coronavirus (SARSCoV) by Calpain Inhibitors and $\beta$-D-N4-Hydroxycytidine. Antivir. Chem. Chemother. 15, 15-22. doi: 10.1177/095632020401500102

Barnard, D. L., Day, C. W., Bailey, K., Heiner, M., Montgomery, R., Lauridsen, L., et al. (2006a). Enhancement of the infectivity of SARS-CoV in BALB/c mice by IMP dehydrogenase inhibitors, including ribavirin. Antiviral Res. 71, 53-63. doi: 10.1016/j.antiviral.2006.03.001

Barnard, D. L., Day, C. W., Bailey, K., Heiner, M., Montgomery, R., Lauridsen, L., et al. (2006b). Evaluation of immunomodulators, interferons and known in vitro SARS-
coV inhibitors for inhibition of SARS-coV replication in BALB/c mice. Antivir. Chem. Chemother. 17, 275-284. doi: 10.1177/095632020601700505

Baron, S. A., Devaux, C., Colson, P., Raoult, D., and Rolain, J.-M. (2020). Teicoplanin: an alternative drug for the treatment of COVID-19? Int. J. Antimicrob. Agents 55, 105944. doi: 10.1016/j.ijantimicag.2020.105944

Beigel, J. H., Tomashek, K. M., Dodd, L. E., Mehta, A. K., Zingman, B. S., Kalil, A. C., et al. (2020). Remdesivir for the Treatment of Covid-19 - Preliminary Report. New Engl. J. Med. doi: 10.1056/NEJMoa2007764

Belouzard, S., Chu, V. C, and Whittaker, G. R. (2009). Activation of the SARS coronavirus spike protein via sequential proteolytic cleavage at two distinct sites Proc. Natl. Acad. Sci. U. S. A. 106, 5871-5876. doi: 10.1073/pnas.0809524106

Billich, A. (2002). Thymosin alpha1. SciClone Pharmaceuticals. Curr. Opin. Invest. Drugs 3, 698-707.

Blaising, J., Polyak, S. J., and Pécheur, E.-I. (2014). Arbidol as a broad-spectrum antiviral: An update. Antiviral Res. 107, 84-94. doi: 10.1016/j.antiviral.2014.04.006

Blanc, C. A., Grist, J. J., Rosen, H., Sears-Kraxberger, I., Steward, O., and Lane, T. E. (2015). Sphingosine-1-Phosphate Receptor Antagonism Enhances Proliferation and Migration of Engrafted Neural Progenitor Cells in a Model of Viral-Induced Demyelination. Am. J. Pathol. 185, 2819-2832. doi: 10.1016/ j.ajpath.2015.06.009

Borba, M. G. S., Val, F. F. A., Sampaio, V. S., Alexandre, M. A. A., Melo, G. C., Brito, M., et al. (2020). Effect of High vs Low Doses of Chloroquine Diphosphate as Adjunctive Therapy for Patients Hospitalized With Severe Acute Respiratory Syndrome Coronavirus 2 (SARS-CoV-2) Infection: A Randomized Clinical Trial. JAMA Netw. Open 3, e208857-e208857. doi: 10.1001/jamanetworkopen.2020.8857

Borges, M. C., Castro, L. A., and da Fonseca, B. A. L. (2013). Chloroquine use improves dengue-related symptoms. Mem. Inst. Oswaldo Cruz 108, 596-599. doi: 10.1590/0074-0276108052013010

Borghi, A., Coronelli, C., Faniuolo, L., Allievi, G., Pallanza, R., and Gallo, G. G. (1984). Teichomycins, new antibiotics from Actinoplanes teichomyceticus nov. sp. IV. Separation and characterization of the components of teichomycin (teicoplanin). J. Antibiot. 37, 615-620. doi: 10.7164/antibiotics.37.615

Bosseboeuf, E., Aubry, M., Nhan, T., de Pina, J. J., Rolain, J. M., Raoult, D., et al. (2018). Azithromycin Inhibits the Replication of Zika Virus. J. Antivir. Antiretrovir. 10, 6-11. doi: 10.4172/1948-5964.1000173

Boulware, D. R., Pullen, M. F., Bangdiwala, A. S., Pastick, K. A., Lofgren, S. M., Okafor, E. C., et al. (2020). A Randomized Trial of Hydroxychloroquine as Postexposure Prophylaxis for Covid-19. New Engl. J. Med. 0, null. doi: 10.1056/ NEJMoa2016638

Burghgraeve, T. D., Kaptein, S. J. F., Ayala-Nunez, N. V., Mondotte, J. A., Pastorino, B., Printsevskaya, S. S., et al. (2012). An Analogue of the Antibiotic Teicoplanin Prevents Flavivirus Entry In Vitro. PloS One 7, e37244. doi: 10.1371/journal.pone.0037244

Cai, Q., Yang, M., Liu, D., Chen, J., Shu, D., Xia, J., et al. (2020). Experimental Treatment with Favipiravir for COVID-19: An Open-Label Control Study. Engineering. doi: 10.1016/j.eng.2020.03.007

Caly, L., Wagstaff, K. M., and Jans, D. A. (2012). Nuclear trafficking of proteins from RNA viruses: Potential target for antivirals? Antiviral Res. 95, 202-206. doi: 10.1016/j.antiviral.2012.06.008

Caly, L., Druce, J. D., Catton, M. G., Jans, D. A., and Wagstaff, K. M. (2020). The FDA-approved Drug Ivermectin inhibits the replication of SARS-CoV-2 in vitro. Antiviral Res. 178, 104787. doi: 10.1016/j.antiviral.2020.104787

Canadian Agency for Drugs and Technologies in Health (2015). "Darunavir/ Cobicistat (Prezcobix)" in Common Drug Review. Available at: https://www. ncbi.nlm.nih.gov/books/NBK362499/

Cao, J., Forrest, J. C., and Zhang, X. (2015). A screen of the NIH Clinical Collection small molecule library identifies potential anti-coronavirus drugs. Antiviral Res. 114, 1-10. doi: 10.1016/j.antiviral.2014.11.010

Cao, B., Wang, Y., Wen, D., Liu, W., Wang, J., Fan, G., et al. (2020). A Trial of Lopinavir-Ritonavir in Adults Hospitalized with Severe Covid-19. N. Engl. J. Med. 382, 1787-1799. doi: 10.1056/NEJMoa2001282

Carraro, G., Naso, A., Montomoli, E., Gasparini, R., Camerini, R., Panatto, D., et al. (2012). Thymosin-alpha 1 (Zadaxin) enhances the immunogenicity of an adjuvated pandemic H1N1v influenza vaccine (Focetria) in hemodialyzed patients: a pilot study. Vaccine 30, 1170-1180. doi: 10.1016/j.vaccine.2011.12.014

Casadevall, A., and Pirofski, L. (2020). The convalescent sera option for containing COVID-19. J. Clin. Invest. 2, 1545-1548. doi: 10.1172/jci138003 
Chadwick, D., Pido-Lopez, J., Pires, A., Imami, N., Gotch, F., Villacian, J. S., et al. (2003). A pilot study of the safety and efficacy of thymosin alpha 1 in augmenting immune reconstitution in HIV-infected patients with low CD4 counts taking highly active antiretroviral therapy. Clin. Exp. Immunol. 134, 477-481. doi: 10.1111/j.1365-2249.2003.02331.x

Chan, J. F.-W., Yao, Y., Yeung, M.-L., Deng, W., Bao, L., Jia, L., et al. (2015). Treatment With Lopinavir/Ritonavir or Interferon- $\beta 1 b$ Improves Outcome of MERS-CoV Infection in a Nonhuman Primate Model of Common Marmoset. J. Infect. Dis. 212, 1904-1913. doi: 10.1093/infdis/jiv392

Chen, F., Chan, K. H., Jiang, Y., Kao, R. Y. T., Lu, H. T., Fan, K. W., et al. (2004). In vitro susceptibility of 10 clinical isolates of SARS coronavirus to selected antiviral compounds. J. Clin. Virol. 31, 69-75. doi: 10.1016/j.jcv.2004.03.003

Chen, C., Zhang, Y., Huang, J., Yin, P., Cheng, Z., Wu, J., et al. (2020). Favipiravir versus Arbidol for COVID-19: A Randomized Clinical Trial. medRxiv 2020. doi: $10.1101 / 2020.03 .17 .20037432$

Chen, L., Liu, W., Zhang, Q., Xu, K., Ye, G., Wu, W., et al. (2020). RNA based mNGS approach identifies a novel human coronavirus from two individual pneumonia cases in 2019 Wuhan outbreak. Emerg. Microbes Infect. 9, 313-319. doi: 10.1080/22221751.2020.1725399

Chen, Y., Liu, Q., and Guo, D. (2020). Emerging coronaviruses: Genome structure, replication, and pathogenesis. J. Med. Virol. 92, 418-423. doi: 10.1002/ jmv. 25681

Cheng, Y., Wong, R., Soo, Y. O. Y., Wong, W. S., Lee, C. K., Ng, M. H. L., et al. (2005). Use of convalescent plasma therapy in SARS patients in Hong Kong. Eur. J. Clin. Microbiol. Infect. Dis. 24, 44-46. doi: 10.1007/s10096-004-1271-9

Chorin, E., Dai, M., Shulman, E., Wadhwani, L., Bar-Cohen, R., Barbhaiya, C., et al. (2020). The QT interval in patients with COVID-19 treated with hydroxychloroquine and azithromycin. Nat. Med. 26, 808-809. doi: 10.1038/ s41591-020-0888-2

Choy, K.-T., Wong, A. Y.-L., Kaewpreedee, P., Sia, S. F., Chen, D., Hui, K. P. Y., et al. (2020). Remdesivir, lopinavir, emetine, and homoharringtonine inhibit SARS-CoV-2 replication in vitro. Antiviral Res. 178, 104786. doi: 10.1016/ j.antiviral.2020.104786

Chu, C. M., Cheng, V. C. C., Hung, I. F. N., Wong, M. M. L., Chan, K. H., Chan, K. S., et al. (2004). Role of lopinavir/ritonavir in the treatment of SARS: initial virological and clinical findings. Thorax 59, 252-256. doi: 10.1136/ thorax.2003.012658

Cinatl, J., Morgenstern, B., Bauer, G., Chandra, P., Rabenau, H., and Doerr, H. (2003). Treatment of SARS with human interferons. Lancet 362, 293-294. doi: 10.1016/S0140-6736(03)13973-6

Corneli, H. M., Zorc, J. J., Mahajan, P., Majahan, P., Shaw, K. N., Holubkov, R., et al. (2007). A multicenter, randomized, controlled trial of dexamethasone for bronchiolitis. N. Engl. J. Med. 357, 331-339. doi: 10.1056/NEJMoa071255

Corti, A., Soffientini, A., and Cassani, G. (1985). Binding of the glycopeptide antibiotic teicoplanin to D-alanyl-D-alanine-agarose: the effect of micellar aggregates. J. Appl. Biochem. 7, 133-137.

Dalbeth, N., Lauterio, T. J., and Wolfe, H. R. (2014). Mechanism of action of colchicine in the treatment of gout. Clin. Ther. 36, 1465-1479. doi: 10.1016/ j.clinthera.2014.07.017

De Clercq, E. (2009). Anti-HIV drugs: 25 compounds approved within 25 years after the discovery of HIV. Int. J. Antimicrob. Agents 33, 307-320. doi: 10.1016/ j.ijantimicag.2008.10.010

de Haan, C. A. M., and Rottier, P. J. M. (2005). Molecular Interactions in the Assembly of Coronaviruses. Adv. Virus Res. 64, 165-230. doi: 10.1016/S00653527(05)64006-7

de Wilde, A. H., Jochmans, D., Posthuma, C. C., Zevenhoven-Dobbe, J. C., van Nieuwkoop, S., Bestebroer, T. M., et al. (2014). Screening of an FDA-Approved Compound Library Identifies Four Small-Molecule Inhibitors of Middle East Respiratory Syndrome Coronavirus Replication in Cell Culture. Antimicrobial. Agents Chemother. 58, 4875-4884. doi: 10.1128/AAC.03011-14

de Wit, E., Feldmann, F., Cronin, J., Jordan, R., Okumura, A., Thomas, T., et al. (2020). Prophylactic and therapeutic remdesivir (GS-5734) treatment in the rhesus macaque model of MERS-CoV infection. Proc. Natl. Acad. Sci. U.S.A. 201922083, 6771-6776. doi: 10.1073/pnas.1922083117

Deftereos, S. G., Giannopoulos, G., Vrachatis, D. A., Siasos, G. D., Giotaki, S. G., Gargalianos, P., et al. (2020). Effect of Colchicine vs Standard Care on Cardiac and Inflammatory Biomarkers and Clinical Outcomes in Patients Hospitalized With Coronavirus Disease 2019: The GRECCO-19 Randomized
Clinical Trial. JAMA Netw. Open 3, e2013136-e2013136. doi: 10.1001/ jamanetworkopen.2020.13136

Delvecchio, R., Higa, L. M., Pezzuto, P., Valadão, A. L., Garcez, P. P., Monteiro, F. L., et al. (2016). Chloroquine, an Endocytosis Blocking Agent, Inhibits Zika Virus Infection in Different Cell Models. Viruses 8, 322. doi: 10.3390/v8120322

Deng, L., Li, C., Zeng, Q., Liu, X., Li, X., Zhang, H., et al. (2020). Arbidol combined with LPV/r versus LPV/r alone against Corona Virus Disease 2019: A retrospective cohort study. J. Infect. 81, 1-5. doi: 10.1016/j.jinf.2020.03.002

Dey, S., Saini, M., Dhembla, C., Bhatt, S., Rajesh, A., Anand, V., et al. (2020). Suramin, Penciclovir and Anidulafungin bind nsp12, which governs the RNAdependent-RNA polymerase activity of SARS-CoV-2, with higher interaction energy than Remdesivir, indicating potential in the treatment of Covid-19 infection. doi: 10.31219/osf.io/urxwh

Dhama, K., Sharun, K., Tiwari, R., Dadar, M., Malik, Y. S., Singh, K. P., et al. (2020). COVID-19, an emerging coronavirus infection: advances and prospects in designing and developing vaccines, immunotherapeutics, and therapeutics. Hum. Vaccines Immunother. 16, 1-7. doi: 10.1080/21645515.2020.1735227

Diao, B., Wang, C., Tan, Y., Chen, X., Liu, Y., Ning, L., et al. (2020). Reduction and Functional Exhaustion of T Cells in Patients With Coronavirus Disease 2019 (COVID-19). Front. Immunol. 11, 827. doi: 10.3389/fimmu.2020.00827

Ding, Q., Lu, P., Fan, Y., Xia, Y., and Liu, M. (2020). The clinical characteristics of pneumonia patients coinfected with 2019 novel coronavirus and influenza virus in Wuhan, China. J. Med. Virol. 1-7. doi: 10.1002/jmv.25781

Dong, L., Hu, S., and Gao, J. (2020). Discovering drugs to treat coronavirus disease 2019 (COVID-19). Drug Discov. Ther. 14, 58-60. doi: 10.5582/ddt.2020.01012

Dotis, J., and Roilides, E. (2009). H1N1 Influenza A infection. Hippokratia 13, $135-138$.

Drosten, C., Günther, S., Preiser, W., van der Werf, S., Brodt, H.-R., Becker, S., et al. (2003). Identification of a novel coronavirus in patients with severe acute respiratory syndrome. N. Engl. J. Med. 348, 1967-1976. doi: 10.1056/ NEJMoa030747

Du, L., He, Y., Zhou, Y., Liu, S., Zheng, B.-J., and Jiang, S. (2009). The spike protein of SARS-CoV - a target for vaccine and therapeutic development. Nat. Rev. Microbiol. 7, 226-236. doi: 10.1038/nrmicro2090

Earnshaw, D. L., Bacon, T. H., Darlison, S. J., Edmonds, K., Perkins, R. M., and Vere Hodge, R. A. (1992). Mode of antiviral action of penciclovir in MRC-5 cells infected with herpes simplex virus type 1 (HSV-1), HSV-2, and varicellazoster virus. Antimicrob. Agents Chemother. 36, 2747-2757. doi: 10.1128/ aac.36.12.2747

Ehteshami, M., Tao, S., Zandi, K., Hsiao, H.-M., Jiang, Y., Hammond, E., et al. (2017). Characterization of $\beta$-d-N4-Hydroxycytidine as a Novel Inhibitor of Chikungunya Virus. Antimicrob. Agents Chemother. 61, e02395-16. doi: 10.1128/AAC.02395-16

Elfiky, A. A. (2020a). Anti-HCV, nucleotide inhibitors, repurposing against COVID-19. Life Sci. 248, 117477. doi: 10.1016/j.lfs.2020.117477

Elfiky, A. A. (2020b). Ribavirin, Remdesivir, Sofosbuvir, Galidesivir, and Tenofovir against SARS-CoV-2 RNA dependent RNA polymerase (RdRp): A molecular docking study. Life Sci. 253. doi: 10.1016/j.lfs.2020.117592

Elkharwili, D. A., Ibrahim, O. M., Elazab, G. A., and Elrifaey, S. M. (2020). Two regimens of dexamethasone versus prednisolone for acute exacerbations in asthmatic Egyptian children. Eur. J. Hosp. Pharm. 27, 151-156. doi: 10.1136/ ejhpharm-2018-001707

Falzarano, D., de Wit, E., Martellaro, C., Callison, J., Munster, V. J., and Feldmann, H. (2013). Inhibition of novel $\beta$ coronavirus replication by a combination of interferon- $\alpha 2$ b and ribavirin. Sci. Rep. 3, 1686. doi: 10.1038/srep01686

Farias, K. J. S., Machado, P. R. L., and da Fonseca, B. A. L. (2013). Chloroquine inhibits dengue virus type 2 replication in Vero cells but not in C6/36 cells. Sci. World J. 2013:282734. doi: 10.1155/2013/282734

Farias, K. J. S., Machado, P. R. L., Muniz, J. A. P. C., Imbeloni, A. A., and da Fonseca, B. A. L. (2015). Antiviral Activity of Chloroquine Against Dengue Virus Type 2 Replication in Aotus Monkeys. Viral. Immunol. 28, 161-169. doi: 10.1089/vim.2014.0090

Fauci, A. S., and Morens, D. M. (2016). Zika Virus in the Americas - Yet Another Arbovirus Threat. New Engl. J. Med. 374, 601-604. doi: 10.1056/ NEJMp1600297

Fehr, A. R., and Perlman, S. (2015). Coronaviruses: An Overview of Their Replication and Pathogenesis. Methods Mol. Biol. 1282, 1-23. doi: 10.1007/ 978-1-4939-2438-7_1 
Foerch, C., Friedauer, L., Bauer, B., Wolf, T., and Adam, E. H. (2020). Severe COVID-19 infection in a patient with multiple sclerosis treated with fingolimod. Multiple Sclerosis Related Disord. 42, 102-180. doi: 10.1016/ j.msard.2020.102180

Fohner, A. E., Sparreboom, A., Altman, R. B., and Klein, T. E. (2017). PharmGKB summary: macrolide antibiotic pathway, pharmacokinetics/pharmacodynamics. Pharmacogenet. Genomics 27, 164-167. doi: 10.1097/FPC.0000000000000270

Food and Drug Administration (1986). Highlights of Prescribing Information. Available at: https://www.accessdata.fda.gov/drugsatfda_docs/label/2018/ 019462s039lbl.pdf

Food and Drug Administration (2009a). Chloroquine Phosphate. Available at: https://www.accessdata.fda.gov/drugsatfda_docs/label/2009/083082s050lbl.pdf (Accessed April 23, 2020).

Food and Drug Administration (2009b). Tablets Stromectol ${ }^{\circledR}$ (Ivermectin). Available at: https://www.accessdata.fda.gov/drugsatfda_docs/label/2009/ 050742s026lbl.pdf

Food and Drug Administration (2010). Zithromax. Available at: https://www. accessdata.fda.gov/drugsatfda_docs/label/2011/050693s017,050710s033, 050711s031,050784s018,050730s026lbl.pdf

Food and Drug Administration (2018). Plaquenil ${ }^{\circledR}$ Hydroxychloroquine Sulfate Tablets, USP. Available at: https://www.accessdata.fda.gov/drugsatfda_docs/ label/2019/009768Orig1s051lbl.pdf (Accessed April 23, 2020).

Food and Drug Administration (2020). Recommendations for Investigational COVID-19 Convalescent Plasma (FDA). Available at: https://www.fda.gov/ vaccines-blood-biologics/investigational-new-drug-ind-or-device-exemptionide-process-cber/recommendations-investigational-covid-19-convalescentplasma (Accessed April 23, 2020).

Food and Drug Administration Drug Approval Package. Kaletra (Lopinavir/ Ritonavir) NDA \#21-226 \& 21-251. Available at: https://www.accessdata.fda. gov/drugsatfda_docs/nda/2000/21-226_Kaletra.cfm (Accessed April 23, 2020).

Food and Drug Administration, C. for D. E (2019). FDA approves tisagenlecleucel for B-cell ALL and tocilizumab for cytokine release syndrome (FDA). Available at: https://www.fda.gov/drugs/resources-information-approved-drugs/fdaapproves-tisagenlecleucel-b-cell-all-and-tocilizumab-cytokine-releasesyndrome (Accessed April 23, 2020).

Food and Drug Adminstration (2020). Coronavirus (COVID-19) Update: FDA Issues Emergency Use Authorization for Potential COVID-19 Treatment. Available at: https://www.fda.gov/news-events/press-announcements/ coronavirus-covid-19-update-fda-issues-emergency-use-authorizationpotential-covid-19-treatment (Accessed May 8, 2020).

Fox, L. M., and Saravolatz, L. D. (2005). Nitazoxanide: a new thiazolide antiparasitic agent. Clin. Infect. Dis. 40, 1173-1180. doi: 10.1086/428839

Freedberg, D. E., Conigliaro, J., Wang, T. C., Tracey, K. J., Callahan, M. V., Abrams, J. A., et al. (2020). Famotidine Use is Associated with Improved Clinical Outcomes in Hospitalized COVID-19 Patients: A Propensity Score Matched Retrospective Cohort Study. Gastroenterology. doi: 10.1053/ j.gastro.2020.05.053

Frieman, M., Yount, B., Heise, M., Kopecky-Bromberg, S. A., Palese, P., and Baric, R. S. (2007). Severe Acute Respiratory Syndrome Coronavirus ORF6 Antagonizes STAT1 Function by Sequestering Nuclear Import Factors on the Rough Endoplasmic Reticulum/Golgi Membrane. J. Virol. 81, 9812-9824. doi: 10.1128/JVI.01012-07

Funk, C. D., Laferrière, C., and Ardakani, A. (2020). A Snapshot of the Global Race for Vaccines Targeting SARS-CoV-2 and the COVID-19 Pandemic. Front. Pharmacol. 11, 937. doi: 10.3389/fphar.2020.00937

Gao, J., Tian, Z., and Yang, X. (2020). Breakthrough: Chloroquine phosphate has shown apparent efficacy in treatment of COVID-19 associated pneumonia in clinical studies. Biosci. Trends 14, 72-73. doi: 10.5582/ bst.2020.01047

Gautret, P., Lagier, J.-C., Parola, P., Hoang, V. T., Meddeb, L., Mailhe, M., et al. (2020). Hydroxychloroquine and azithromycin as a treatment of COVID-19: results of an open-label non-randomized clinical trial. Int. J. Antimicrobial. Agents, 56, 105949. doi: 10.1016/j.ijantimicag.2020.105949

Geffin, R., Martinez, R., de las Pozas, A., Issac, B., and McCarthy, M. (2017). Fingolimod induces neuronal-specific gene expression with potential neuroprotective outcomes in maturing neuronal progenitor cells exposed to HIV. J. Neurovirol. 23, 808-824. doi: 10.1007/s13365-017-0571-7
Geleris, J., Sun, Y., Platt, J., Zucker, J., Baldwin, M., Hripcsak, G., et al. (2020). Observational Study of Hydroxychloroquine in Hospitalized Patients with Covid-19. New Engl. J. Med. 382, 2411-2418. doi: 10.1056/NEJMoa2012410

Giacomelli, A., Pezzati, L., Conti, F., Bernacchia, D., Siano, M., Oreni, L., et al. Selfreported Olfactory and Taste Disorders in Patients With Severe Acute Respiratory Coronavirus 2 Infection: A Cross-sectional Study. Clin. Infect. Dis 71, 889-890. doi: 10.1093/cid/ciaa330

Gielen, V., Johnston, S. L., and Edwards, M. R. (2010). Azithromycin induces antiviral responses in bronchial epithelial cells. Eur. Respir. J. 36, 646-654. doi: 10.1183/09031936.00095809

Gierer, S., Bertram, S., Kaup, F., Wrensch, F., Heurich, A., Krämer-Kühl, A., et al. (2013). The Spike Protein of the Emerging Betacoronavirus EMC Uses a Novel Coronavirus Receptor for Entry, Can Be Activated by TMPRSS2, and Is Targeted by Neutralizing Antibodies. J. Virol. 87, 5502-5511. doi: 10.1128/ JVI.00128-13

GILEAD (2020). Gilead Presents Additional Data on Investigational Antiviral Remdesivir for the Treatment of COVID-19. Available at: https://www.gilead. com/news-and-press/press-room/press-releases/2020/7/gilead-presentsadditional-data-on-investigational-antiviral-remdesivir-for-the-treatment-ofcovid-19 (Accessed July 13, 2020).

Goldman, J. D., Lye, D. C. B., Hui, D. S., Marks, K. M., Bruno, R., Montejano, R., et al. (2020). Remdesivir for 5 or 10 Days in Patients with Severe Covid-19. New Engl. J. Med. doi: 10.1056/NEJMoa2015301

González Canga, A., Sahagún Prieto, A. M., Diez Liébana, M. J., Fernández Martínez, N., Sierra Vega, M., and García Vieitez, J. J. (2008). The Pharmacokinetics and Interactions of Ivermectin in Humans-A Minireview. AAPS J. 10, 42-46. doi: 10.1208/s12248-007-9000-9

Götz, V., Magar, L., Dornfeld, D., Giese, S., Pohlmann, A., Höper, D., et al. (2016). Influenza $\mathrm{A}$ viruses escape from $\mathrm{MxA}$ restriction at the expense of efficient nuclear vRNP import. Sci. Rep. 6, 1-15. doi: 10.1038/srep23138

Grein, J., Ohmagari, N., Shin, D., Diaz, G., Asperges, E., Castagna, A., et al. (2020). Compassionate Use of Remdesivir for Patients with Severe Covid-19. New Engl. J. Med 382, 2327-2336. doi: 10.1056/NEJMoa2007016

Guaraldi, G., Meschiari, M., Cozzi-Lepri, A., Milic, J., Tonelli, R., Menozzi, M., et al. (2020). Tocilizumab in patients with severe COVID-19: a retrospective cohort study. Lancet Rheumatol. doi: 10.1016/S2665-9913(20)30173-9

Guedj, J., Piorkowski, G., Jacquot, F., Madelain, V., Nguyen, T. H. T., Rodallec, A., et al. (2018). Antiviral efficacy of favipiravir against Ebola virus: A translational study in cynomolgus macaques. PloS Med. 15, e1002535. doi: 10.1371/ journal.pmed.1002535

Harrison, C. (2020a). Coronavirus puts drug repurposing on the fast track. Nat. Biotechnol. 38, 379-381. doi: 10.1038/d41587-020-00003-1

Harrison, C. (2020b). Drug researchers pursue new lines of attack against COVID19. Nat. Biotechnol. 38, 659-662. doi: 10.1038/d41587-020-00013-Z

Haviernik, J., Štefánik, M., Fojtíková, M., Kali, S., Tordo, N., Rudolf, I., et al. (2018). Arbidol (Umifenovir): A Broad-Spectrum Antiviral Drug That Inhibits Medically Important Arthropod-Borne Flaviviruses. Viruses 10, 184 doi: $10.3390 / v 10040184$

Hayden, F. G., and Shindo, N. (2019). Influenza virus polymerase inhibitors in clinical development. Curr. Opin. Infect. Dis. 32, 176-186. doi: 10.1097/ QCO.0000000000000532

He, B., Zhang, Y., Xu, L., Yang, W., Yang, F., Feng, Y., et al. (2014). Identification of Diverse Alphacoronaviruses and Genomic Characterization of a Novel Severe Acute Respiratory Syndrome-Like Coronavirus from Bats in China. J. Virol. 88, 7070-7082. doi: 10.1128/JVI.00631-14

Herod, M. R., Adeyemi, O. O., Ward, J., Bentley, K., Harris, M., Stonehouse, N. J., et al. (2019). The broad-spectrum antiviral drug arbidol inhibits foot-andmouth disease virus genome replication. J. Gen. Virol. 100, 1293-1302. doi: $10.1099 /$ jgv.0.001283

Hilgenfeld, R. (2014). From SARS to MERS: crystallographic studies on coronaviral proteases enable antiviral drug design. FEBS J. 281, 4085-4096. doi: $10.1111 /$ febs.12936

Hoffmann, M., Kleine-Weber, H., Schroeder, S., Krüger, N., Herrler, T., Erichsen, S., et al. (2020). SARS-CoV-2 Cell Entry Depends on ACE2 and TMPRSS2 and Is Blocked by a Clinically Proven Protease Inhibitor. Cell. 781, 271-280. doi: 10.1016/j.cell.2020.02.052

Horby, P., and Landray, M. (2020a). No clinical benefit from use of hydroxychloroquine in hospitalised patients with COVID-19 - RECOVERY 
Trial. Available at: https://www.recoverytrial.net/news/statement-from-thechief-investigators-of-the-randomised-evaluation-of-covid-19-therapyrecovery-trial-on-hydroxychloroquine-5-june-2020-no-clinical-benefit-fromuse-of-hydroxychloroquine-in-hospitalised-patients-with-covid-19 (Accessed July 10, 2020).

Horby, P., and Landray, M. (2020b). No clinical benefit from use of lopinavirritonavir in hospitalised COVID-19 patients studied in RECOVERY. Available at: https://www.recoverytrial.net/news/no-clinical-benefit-from-use-oflopinavir-ritonavir-in-hospitalised-covid-19-patients-studied-in-recovery

Hsiang, S., Allen, D., Annan-Phan, S., Bell, K., Bolliger, I., Chong, T., et al. (2020). The effect of large-scale anti-contagion policies on the COVID-19 pandemic. Nature, 1-9. doi: 10.1038/s41586-020-2404-8

Hsu, L.-Y., Lee, C.-C., Green, J. A., Ang, B., Paton, N.II, Lee, L., et al. (2003). Severe Acute Respiratory Syndrome (SARS) in Singapore: Clinical Features of Index Patient and Initial Contacts. Emerg. Infect. Dis. 9, 713-717. doi: 10.3201/ eid0906.030264

Huang, K.-J., Su, I.-J., Theron, M., Wu, Y.-C., Lai, S.-K., Liu, C.-C., et al. (2005). An interferon-gamma-related cytokine storm in SARS patients. J. Med. Virol. 75, 185-194. doi: 10.1002/jmv.20255

Huang, C., Wang, Y., and Li, X. (2020). Clinical features of patients infected with 2019 novel coronavirus in Wuhan, China. Lancet 395, 496-496. doi: 10.1016/ s0140-6736(20)30252-x

Hung, I. F.-N., Lung, K.-C., Tso, E. Y.-K., Liu, R., Chung, T. W.-H., Chu, M.-Y., et al. (2020). Triple combination of interferon beta-1b, lopinavir-ritonavir, and ribavirin in the treatment of patients admitted to hospital with COVID-19: an open-label, randomised, phase 2 trial. Lancet 395, 1695-1704. doi: 10.1016/ S0140-6736(20)31042-4

Hurst, K. R., Kuo, L., Koetzner, C. A., Ye, R., Hsue, B., and Masters, P. S. (2005). A Major Determinant for Membrane Protein Interaction Localizes to the Carboxy-Terminal Domain of the Mouse Coronavirus Nucleocapsid Protein. J. Virol. 79, 13285-13297. doi: 10.1128/JVI.79.21.1328513297.2005

Iino, S., Toyota, J., Kumada, H., Kiyosawa, K., Kakumu, S., Sata, M., et al. (2005). The efficacy and safety of thymosin alpha-1 in Japanese patients with chronic hepatitis B; results from a randomized clinical trial. J. Viral. Hepat. 12, 300306. doi: $10.1111 / j .1365-2893.2005 .00633 . x$

Ikeda, T. (2003). Pharmacological effects of ivermectin, an antiparasitic agent for intestinal strongyloidiasis: its mode of action and clinical efficacy. Nippon Yakurigaku Zasshi 122, 527-538. doi: 10.1254/fpj.122.527

Janowitz, T., Gablenz, E., Pattinson, D., Wang, T. C., Conigliaro, J., Tracey, K., et al. (2020). Famotidine use and quantitative symptom tracking for COVID19 in non-hospitalised patients: a case series. Gut. doi: 10.1136/gutjnl-2020321852

Jans, D. A., Martin, A. J., and Wagstaff, K. M. (2019). Inhibitors of nuclear transport. Curr. Opin. Cell Biol. 58, 50-60. doi: 10.1016/j.ceb.2019.01.001

Jasenosky, L. D., Cadena, C., Mire, C. E., Borisevich, V., Haridas, V., Ranjbar, S., et al. (2019). The FDA-Approved Oral Drug Nitazoxanide Amplifies Host Antiviral Responses and Inhibits Ebola Virus. iScience 19, 1279-1290. doi: 10.1016/j.isci.2019.07.003

Ji, S.-M., Li, L.-S., Sun, Q.-Q., Chen, J.-S., Sha, G.-Z., and Liu, Z.-H. (2007). Immunoregulation of thymosin alpha 1 treatment of cytomegalovirus infection accompanied with acute respiratory distress syndrome after renal transplantation. Transpl. Proc. 39, 115-119. doi: 10.1016/j.transproceed.2006.10.005

Joyner, M. J., Wright, R. S., Fairweather, D., Senefeld, J. W., Bruno, K. A., Klassen, S. A., et al. (2020). Early safety indicators of COVID-19 convalescent plasma in 5,000 patients. J. Clin. Invest. doi: 10.1172/JCI140200

Jun, C., Yun, L., Xiuhong, X., Ping, L., Feng, L., Tao, L., et al. (2020). Efficacies of lopinavir/ritonavir and abidol in the treatment of novel coronavirus pneumonia. Chin. J. Infect. Dis. 38, E008-E008. doi: 10.3760/ cma.j.cn311365-20200210-00050

Kaner, R. J., Ladetto, J. V., Singh, R., Fukuda, N., Matthay, M. A., and Crystal, R. G. (2000). Lung overexpression of the vascular endothelial growth factor gene induces pulmonary edema. Am. J. Respir. Cell Mol. Biol. 22, 657-664. doi: 10.1165/ajrcmb.22.6.3779

Kang, C. K., Seong, M.-W., Choi, S.-J., Kim, T. S., Choe, P. G., Song, S. H., et al. (2020). In vitro activity of lopinavir/ritonavir and hydroxychloroquine against severe acute respiratory syndrome coronavirus 2 at concentrations achievable by usual doses. Korean J. Intern. Med. 35, 782-787. doi: 10.3904/kjim.2020.157
Kewan, T., Covut, F., Al-Jaghbeer, M. J., Rose, L., Gopalakrishna, K. V., and Akbik, B. (2020). Tocilizumab for treatment of patients with severe COVID19: A retrospective cohort study. EClinicalMedicine 0, 100418. doi: 10.1016/ j.eclinm.2020.100418

Keyaerts, E., Vijgen, L., Maes, P., Neyts, J., and Ranst, M. V. (2004). In vitro inhibition of severe acute respiratory syndrome coronavirus by chloroquine. Biochem. Biophys. Res. Commun. 323, 264-268. doi: 10.1016/ j.bbrc.2004.08.085

Keyaerts, E., Li, S., Vijgen, L., Rysman, E., Verbeeck, J., Ranst, M. V., et al. (2009). Antiviral Activity of Chloroquine against Human Coronavirus OC43 Infection in Newborn Mice. Antimicrobial. Agents Chemother. 53, 3416-3421. doi: 10.1128/AAC.01509-08

Khamitov, R. A., Loginova, S.II, Shchukina, V. N., Borisevich, S. V., Maksimov, V. A., and Shuster, A. M. (2008). [Antiviral activity of arbidol and its derivatives against the pathogen of severe acute respiratory syndrome in the cell cultures]. Vopr. Virusol. 53, 9-13.

Kiselev, O.II, Deeva, E. G., Mel'nikova, T.II, Kozeletskaia, K. N., Kiselev, A. S., Rusinov, V. L., et al. (2012). [A new antiviral drug Triazavirin: results of phase II clinical trial]. Vopr. Virusol. 57, 9-12.

Ko, J. H., Seok, H., Cho, S. Y., Ha, Y. E., Baek, J. Y., Kim, S. H., et al. (2018). Challenges of convalescent plasma infusion therapy in Middle East respiratory coronavirus infection: A single centre experience. Antiviral Ther. 23, 617-622. doi: 10.3851/IMP3243

Kono, M., Tatsumi, K., Imai, A. M., Saito, K., Kuriyama, T., and Shirasawa, H. (2008). Inhibition of human coronavirus $229 \mathrm{E}$ infection in human epithelial lung cells (L132) by chloroquine: Involvement of p38 MAPK and ERK. Antiviral Res. 77, 150-152. doi: 10.1016/j.antiviral.2007.10.011

Korba, B. E., Montero, A. B., Farrar, K., Gaye, K., Mukerjee, S., Ayers, M. S., et al. (2008). Nitazoxanide, tizoxanide and other thiazolides are potent inhibitors of hepatitis B virus and hepatitis C virus replication. Antiviral Res. 77, 56-63. doi: 10.1016/j.antiviral.2007.08.005

Koren, G., King, S., Knowles, S., and Phillips, E. (2003). Ribavirin in the treatment of SARS: A new trick for an old drug? CMAJ 168, 1289-1292.

Kullavanuaya, P., Treeprasertsuk, S., Thong-Ngam, D., Chaermthai, K., Gonlachanvit, S., and Suwanagool, P. (2001). The combined treatment of interferon alpha-2a and thymosin alpha 1 for chronic hepatitis C: the 48 weeks end of treatment results. J. Med. Assoc. Thai 84 (Suppl 1), S462-S468.

La Frazia, S., Ciucci, A., Arnoldi, F., Coira, M., Gianferretti, P., Angelini, M., et al. (2013). Thiazolides, a new class of antiviral agents effective against rotavirus infection, target viral morphogenesis, inhibiting viroplasm formation. J. Virol. 87, 11096-11106. doi: 10.1128/JVI.01213-13

Lauer, S. A., Grantz, K. H., Bi, Q., Jones, F. K., Zheng, Q., Meredith, H. R., et al. (2020). The Incubation Period of Coronavirus Disease 2019 (COVID-19) From Publicly Reported Confirmed Cases: Estimation and Application. Ann. Intern. Med. 172, 577-582. doi: 10.7326/M20-0504

Leneva, I. A., Sokolova, M. V., Fediakina, I. T., Khristova, M. L., Fadeeva, N.II, and Gus'kova, T. A. (2002). [Study of the effect of antiviral drugs on the reproduction of the respiratory syncytial virus by enzyme immunoassay]. Vopr. Virusol. 47, 42-45.

Leung, Y. Y., Yao Hui, L. L., and Kraus, V. B. (2015). Colchicine-Update on mechanisms of action and therapeutic uses. Semin. Arthritis Rheum. 45, 341350. doi: 10.1016/j.semarthrit.2015.06.013

Li, W., Moore, M. J., Vasilieva, N., Sui, J., Wong, S. K., Berne, M. A., et al. (2003). Angiotensin-converting enzyme 2 is a functional receptor for the SARS coronavirus. Nature 426, 450-454. doi: 10.1038/nature02145

Li, F., Li, W., Farzan, M., and Harrison, S. C. (2005). Structure of SARS coronavirus spike receptor-binding domain complexed with receptor. Science 309, 1864-1868. doi: 10.1126/science.1116480

Li, C., Zhu, X., Ji, X., Quanquin, N., Deng, Y.-Q., Tian, M., et al. (2017) Chloroquine, a FDA-approved Drug, Prevents Zika Virus Infection and its Associated Congenital Microcephaly in Mice. EBioMedicine 24, 189-194. doi: 10.1016/j.ebiom.2017.09.034

Li, C., Zu, S., Deng, Y.-Q., Li, D., Parvatiyar, K., Quanquin, N., et al. (2019). Azithromycin Protects against Zika virus Infection by Upregulating virusinduced Type I and III Interferon Responses. Antimicrob. Agents Chemother. 63, e00394-19. doi: 10.1128/AAC.00394-19

Li, L., Zhang, W., Hu, Y., Tong, X., Zheng, S., Yang, J., et al. (2020). Effect of Convalescent Plasma Therapy on Time to Clinical Improvement in Patients 
With Severe and Life-threatening COVID-19: A Randomized Clinical Trial. JAMA e201004. doi: 10.1001/jama.2020.10044

Li, Y., Xie, Z., Lin, W., Cai, W., Wen, C., Guan, Y., et al. (2020). Efficacy and Safety of Lopinavir/Ritonavir or Arbidol in Adult Patients with Mild/Moderate COVID-19: An Exploratory Randomized Controlled Trial. Med. doi: 10.1016/j.medj.2020.04.001

Liu, S., Xiao, G., Chen, Y., He, Y., Niu, J., Escalante, C. R., et al. (2004). Interaction between heptad repeat 1 and 2 regions in spike protein of SARS-associated coronavirus: implications for virus fusogenic mechanism and identification of fusion inhibitors. Lancet 363, 938-947. doi: 10.1016/S0140-6736(04)15788-7

Liu, J., Cao, R., Xu, M., Wang, X., Zhang, H., Hu, H., et al. (2020). Hydroxychloroquine, a less toxic derivative of chloroquine, is effective in inhibiting SARS-CoV-2 infection in vitro. Cell Discovery 6, 16. doi: 10.1038/ s41421-020-0156-0

Liu, S. T. H., Lin, H.-M., Baine, I., Wajnberg, A., Gumprecht, J. P., Rahman, F., et al. (2020). Convalescent plasma treatment of severe COVID-19: A matched control study. medRxiv 2020. doi: 10.1101/2020.05.20.20102236

Liu, Y., Pang, Y., Hu, Z., Wu, M., Wang, C., Feng, Z., et al. (2020). Thymosin alpha $1(\mathrm{~T} \alpha 1)$ reduces the mortality of severe COVID-19 by restoration of lymphocytopenia and reversion of exhausted $\mathrm{T}$ cells. Clin. Infect. Dis. doi: $10.1093 / \mathrm{cid} / \mathrm{ciaa} 630$

Lo, M. K., Jordan, R., Arvey, A., Sudhamsu, J., Shrivastava-Ranjan, P., Hotard, A. L., et al. (2017). GS-5734 and its parent nucleoside analog inhibit Filo-, Pneumo-, and Paramyxoviruses. Sci. Rep. 7:43395. doi: 10.1038/srep43395

Lo, M. K., Feldmann, F., Gary, J. M., Jordan, R., Bannister, R., Cronin, J., et al. (2019). Remdesivir (GS-5734) protects African green monkeys from Nipah virus challenge. Sci. Transl. Med. 11, eaau9242. doi: 10.1126/scitranslmed.aau9242

Low, T. L., and Goldstein, A. L. (1984). Thymosins: structure, function and therapeutic applications. Thymus 6, 27-42.

Lu, R., Zhao, X., Li, J., Niu, P., Yang, B., Wu, H., et al. (2020). Genomic characterisation and epidemiology of 2019 novel coronavirus: implications for virus origins and receptor binding. Lancet 395, 565-574. doi: 10.1016/ S0140-6736(20)30251-8

Lundberg, L., Pinkham, C., Baer, A., Amaya, M., Narayanan, A., Wagstaff, K. M., et al. (2013). Nuclear import and export inhibitors alter capsid protein distribution in mammalian cells and reduce Venezuelan Equine Encephalitis Virus replication. Antiviral Res. 100, 662-672. doi: 10.1016/j.antiviral.2013.10.004

Luo, P., Liu, Y., Qiu, L., Liu, X., Liu, D., and Li, J. (2020). Tocilizumab treatment in COVID-19: A single center experience. J. Med. Virol. 92, 814-818. doi: 10.1002/jmv.25801

Lv, C., Liu, W., Wang, B., Dang, R., Qiu, L., Ren, J., et al. (2018). Ivermectin inhibits DNA polymerase UL42 of pseudorabies virus entrance into the nucleus and proliferation of the virus in vitro and vivo. Antiviral Res. 159, 55-62. doi: 10.1016/j.antiviral.2018.09.010

Madrid, P. B., Panchal, R. G., Warren, T. K., Shurtleff, A. C., Endsley, A. N., Green, C. E., et al. (2015). Evaluation of Ebola Virus Inhibitors for Drug Repurposing. ACS Infect. Dis. 1, 317-326. doi: 10.1021/acsinfecdis.5b00030

Magagnoli, J., Narendran, S., Pereira, F., Cummings, T. H., Hardin, J. W., Sutton, S. S., et al. (2020). Outcomes of Hydroxychloroquine Usage in United States Veterans Hospitalized with COVID-19. Med. doi: 10.1016/j.medj.2020.06.001

Mahallawi, W. H., Khabour, O. F., Zhang, Q., Makhdoum, H. M., and Suliman, B. A. (2018). MERS-CoV infection in humans is associated with a proinflammatory Th1 and Th17 cytokine profile. Cytokine 104, 8-13. doi: $10.1016 /$ j.cyto.2018.01.025

Maieron, A., and Kerschner, H. (2012). Teicoplanin therapy leading to a significant decrease in viral load in a patient with chronic hepatitis C. J. Antimicrob. Chemother. 67, 2537-2538. doi: 10.1093/jac/dks217

Maio, M., Mackiewicz, A., Testori, A., Trefzer, U., Ferraresi, V., Jassem, J., et al. (2010). Large Randomized Study of Thymosin $\alpha$ 1, Interferon Alfa, or Both in Combination With Dacarbazine in Patients With Metastatic Melanoma. JCO 28, 1780-1787. doi: 10.1200/JCO.2009.25.5208

Manni, A., Direnzo, V., Iaffaldano, A., Lecce, V. D., Tortorella, C., Zoccolella, S., et al. (2017). Gender differences in safety issues during Fingolimod therapy: Evidence from a real-life Relapsing Multiple Sclerosis cohort. Brain Behav. 7, e00804. doi: 10.1002/brb3.804

Mastrangelo, E., Pezzullo, M., De Burghgraeve, T., Kaptein, S., Pastorino, B., Dallmeier, K., et al. (2012). Ivermectin is a potent inhibitor of flavivirus replication specifically targeting NS3 helicase activity: new prospects for an old drug. J. Antimicrob. Chemother. 67, 1884-1894. doi: 10.1093/jac/dks147

Matsuyama, S., Nao, N., Shirato, K., Kawase, M., Saito, S., Takayama, I., et al. (2020). Enhanced isolation of SARS-CoV-2 by TMPRSS2-expressing cells. PNAS 117, 7001-7003. doi: 10.1073/pnas.2002589117

McCreary, E. K., and Pogue, J. M. (2020). Coronavirus Disease 2019 Treatment: A Review of Early and Emerging Options. Open Forum Infect. Dis. 7, ofaa105. doi: 10.1093/ofid/ofaa105

McGee, S., and Hirschmann, J. (2008). Use of Corticosteroids in Treating Infectious Diseases. Arch. Intern. Med. 168, 1034-1046. doi: 10.1001/ archinte.168.10.1034

Medford, A. R. L., and Millar, A. B. (2006). Vascular endothelial growth factor (VEGF) in acute lung injury (ALI) and acute respiratory distress syndrome (ARDS): Paradox or paradigm? Thorax 61, 621-626. doi: 10.1136/ thx.2005.040204

Mehta, P., Mcauley, D. F., Brown, M., Sanchez, E., Tattersall, R. S., Manson, J. J., et al. (2020). Correspondence COVID-19: consider cytokine storm syndromes and. Lancet 6736, 19-20. doi: 10.1016/S0140-6736(20)30628-0

Merad, M., and Martin, J. C. (2020). Pathological inflammation in patients with COVID-19: a key role for monocytes and macrophages. Nat. Rev. Immunol. 20, 355-362. doi: 10.1038/s41577-020-0331-4

Mitjà, O., Corbacho-Monné, M., Ubals, M., Tebe, C., Peñafiel, J., Tobias, A., et al. (2020). Hydroxychloroquine for Early Treatment of Adults with Mild Covid19: A Randomized-Controlled Trial. Clin. Infect. Dis. doi: 10.1093/cid/ciaa1009

Mondal, D. (2016). Penciclovir 论. Ref. Module Biomed. Sci. 1-4. doi: 10.1016/ B978-0-12-801238-3.99398-X

Monteil, V., Kwon, H., Prado, P., Hagelkrüys, A., Wimmer, R. A., Stahl, M., et al. (2020). Inhibition of SARS-CoV-2 Infections in Engineered Human Tissues Using Clinical-Grade Soluble Human ACE2. Cell. 181, 905-913. doi: 10.1016/ j.cell.2020.04.004

Moscona, A. (2005). Neuraminidase Inhibitors for Influenza. New Engl. J. Med. 353, 1363-1373. doi: 10.1056/NEJMra050740

Mulangu, S., Dodd, L. E., Davey, R. T., Tshiani Mbaya, O., Proschan, M., Mukadi, D., et al. (2019). A Randomized, Controlled Trial of Ebola Virus Disease Therapeutics. New Engl. J. Med. 381, 2293-2303. doi: 10.1056/NEJMoa1910993

Murray, B. E., Arias, C. A., and Nannini, E. C. (2015). "30 - Glycopeptides (Vancomycin and Teicoplanin), Streptogramins (Quinupristin-Dalfopristin), Lipopeptides (Daptomycin), and Lipoglycopeptides (Telavancin)," in Mandell, Douglas, and Bennett"s Principles and Practice of Infectious Diseases (Eighth Edition). Eds. J. E. Bennett, R. Dolin and M. J. Blaser (Philadelphia: Content Repository Only!), 377-400. doi: 10.1016/B978-1-4557-4801-3.00030-8

Nagata, T., Lefor, A. K., Hasegawa, M., and Ishii, M. (2015). Favipiravir: a new medication for the Ebola virus disease pandemic. Disaster Med. Public Health Prep. 9, 79-81. doi: 10.1017/dmp.2014.151

National Institute of Diabetes and Digestive and Kidney Diseases (2012). "Chloroquine" in LiverTox: Clinical and Research Information on DrugInduced Liver Injury. Available form: https://www.ncbi.nlm.nih.gov/books/ NBK548224/

Ni, Y.-N., Chen, G., Sun, J., Liang, B.-M., and Liang, Z.-A. (2019). The effect of corticosteroids on mortality of patients with influenza pneumonia: a systematic review and meta-analysis. Crit. Care 23, 99. doi: 10.1186/s13054-019-2395-8

Nicholls, J. M., Poon, L. L., Lee, K. C., Ng, W. F., Lai, S. T., Leung, C. Y., et al. (2003). Lung pathology of fatal severe acute respiratory syndrome. Lancet 361, 1773-1778. doi: 10.1016/S0140-6736(03)13413-7

Nichols, W. G., Peck Campbell, A. J., and Boeckh, M. (2008). Respiratory Viruses Other than Influenza Virus: Impact and Therapeutic Advances. Clin. Microbiol. Rev. 21, 274-290. doi: 10.1128/CMR.00045-07

Noell, B. C., Besur, S. V., and deLemos, A. S. (2015). Changing the face of hepatitis C management - the design and development of sofosbuvir. Drug Des. Devel. Ther. 9, 2367-2374. doi: 10.2147/DDDT.S65255

Obeid, S., Printsevskaya, S. S., Olsufyeva, E. N., Dallmeier, K., Durantel, D., Zoulim, F., et al. (2011). Inhibition of hepatitis C virus replication by semisynthetic derivatives of glycopeptide antibiotics. J. Antimicrob. Chemother. 66, 1287-1294. doi: 10.1093/jac/dkr104

Ooi, E. E., Chew, J. S. W., Loh, J. P., and Chua, R. C. (2006). In vitro inhibition of human influenza A virus replication by chloroquine. Virol. J. 3, 39. doi: 10.1186/1743-422X-3-39 
Painter, G. R., Bowen, R. A., Bluemling, G. R., DeBergh, J., Edpuganti, V., Gruddanti, P. R., et al. (2019). The prophylactic and therapeutic activity of a broadly active ribonucleoside analog in a murine model of intranasal venezuelan equine encephalitis virus infection. Antiviral Res. 171:104597. doi: 10.1016/j.antiviral.2019.104597

Pan, L., Mu, M., Yang, P., Sun, Y., Wang, R., Yan, J., et al. (2020). Clinical Characteristics of COVID-19 Patients With Digestive Symptoms in Hubei, China: A Descriptive, Cross-Sectional, Multicenter Study. Am. J. Gastroenterol. 115, 766-773. doi: 10.14309/ajg.0000000000000620

Parente, D. M., and Laplante, K. L. (2017). "145 - Glycopeptides," in Infectious Diseases (Fourth Edition), 1249-1255.e2. doi: 10.1016/B978-0-7020-62858.00145-3

Parenti, F., Beretta, G., Berti, M., and Arioli, V. (1978). Teichomycins, new antibiotics from Actinoplanes teichomyceticus Nov. Sp. I. doi: 10.7164/ antibiotics. 31.276

Parhizgar, A. R., and Tahghighi, A. (2017). Introducing New Antimalarial Analogues of Chloroquine and Amodiaquine: A Narrative Review. Iran J. Med. Sci. 42, 115-128.

Paton, N.II, Goodall, R. L., Dunn, D. T., Franzen, S., Collaco-Moraes, Y., Gazzard, B. G., et al. (2012). Effects of hydroxychloroquine on immune activation and disease progression among HIV-infected patients not receiving antiretroviral therapy: a randomized controlled trial. JAMA 308, 353-361. doi: 10.1001/ jama.2012.6936

Pécheur, E.-I., Borisevich, V., Halfmann, P., Morrey, J. D., Smee, D. F., Prichard, M., et al. (2016). The Synthetic Antiviral Drug Arbidol Inhibits Globally Prevalent Pathogenic Viruses. J. Virol. 90, 3086-3092. doi: 10.1128/JVI.02077-15

Petherick, A. (2020). Developing antibody tests for SARS-CoV-2. Lancet 395, 1101-1102. doi: 10.1016/S0140-6736(20)30788-1

Pfender, N., Jelcic, I., Linnebank, M., Schwarz, U., and Martin, R. (2015). Reactivation of herpesvirus under fingolimod: A case of severe herpes simplex encephalitis. Neurology 84, 2377-2378. doi: 10.1212/WNL.0000000000001659

Phan, T. (2020). Novel coronavirus: From discovery to clinical diagnostics. Infection Genet. Evol. 79, 104211. doi: 10.1016/j.meegid.2020.104211

Pino, M., Paganini, S., Deleage, C., Padhan, K., Harper, J. L., King, C. T., et al. (2019). Fingolimod retains cytolytic T cells and limits T follicular helper cell infection in lymphoid sites of SIV persistence. PloS Pathog. 15, e1008081. doi: 10.1371/journal.ppat.1008081

Poutanen, S. M., Low, D. E., Henry, B., Finkelstein, S., Rose, D., Green, K., et al. (2003). Identification of Severe Acute Respiratory Syndrome in Canada. New Engl. J. Med. 348, 1995-2005. doi: 10.1056/NEJMoa030634

Preobrazhenskaya, M. N., and Olsufyeva, E. N. (2006). Polycyclic peptide and glycopeptide antibiotics and their derivatives as inhibitors of HIV entry. Antiviral Res. 71, 227-236. doi: 10.1016/j.antiviral.2006.04.008

Pyrc, K., Bosch, B. J., Berkhout, B., Jebbink, M. F., Dijkman, R., Rottier, P., et al. (2006). Inhibition of Human Coronavirus NL63 Infection at Early Stages of the Replication Cycle. Antimicrobial. Agents Chemother. 50, 2000-2008. doi: 10.1128/AAC.01598-05

Razonable, R. R. (2011). Antiviral Drugs for Viruses Other Than Human Immunodeficiency Virus. Mayo Clin. Proc. 86, 1009-1026. doi: 10.4065/ mcp.2011.0309

Recalcati, S. (2020). Cutaneous manifestations in COVID-19: a first perspective. J. Eur. Acad. Dermatol. Venereol. 34, e212-e213. doi: 10.1111/jdv.16387

Redelman-Sidi, G., Michielin, O., Cervera, C., Ribi, C., Aguado, J. M., FernándezRuiz, M., et al. (2018). ESCMID Study Group for Infections in Compromised Hosts (ESGICH) Consensus Document on the safety of targeted and biological therapies: an infectious diseases perspective (Immune checkpoint inhibitors, cell adhesion inhibitors, sphingosine-1-phosphate receptor modulators and proteasome inhibitors). Clin. Microbiol. Infection 24, S95-S107. doi: 10.1016/ j.cmi.2018.01.030

Regeneron Pharmaceuticals. Inc (2020). Regeneron and Sanofi Provide Update on U.S. Phase 2/3 Adaptive-Designed Trial of Kevzara ${ }^{\circledR}$ (sarilumab) in Hospitalized COVID-19 Patients (Regeneron Pharmaceuticals Inc). Available at: https://newsroom.regeneron.com/index.php/news-releases/news-releasedetails/regeneron-and-sanofi-provide-update-us-phase-23-adaptive (Accessed May 8, 2020).

Reynard, O., Nguyen, X.-N., Alazard-Dany, N., Barateau, V., Cimarelli, A., and Volchkov, V. E. (2015). Identification of a New Ribonucleoside Inhibitor of Ebola Virus Replication. Viruses 7, 6233-6240. doi: 10.3390/v7122934
Romanelli, F., Smith, K. M., and Hoven, A. D. (2004). Chloroquine and hydroxychloroquine as inhibitors of human immunodeficiency virus (HIV1) activity. Curr. Pharm. Des. 10, 2643-2648. doi: 10.2174/1381612043383791

Rosenke, K., Feldmann, H., Westover, J. B., Hanley, P. W., Martellaro, C., Feldmann, F., et al. (2018). Use of Favipiravir to Treat Lassa Virus Infection in Macaques - Volume 24, Number 9-September 2018 - Emerging Infectious. Dis. J. - CDC. 24, 1696-1699. doi: 10.3201/eid2409.180233

Rossignol, J.-F. (2014). Nitazoxanide: A first-in-class broad-spectrum antiviral agent. Antiviral Res. 110, 94-103. doi: 10.1016/j.antiviral.2014.07.014

Rossignol, J.-F. (2016). Nitazoxanide, a new drug candidate for the treatment of Middle East respiratory syndrome coronavirus. J. Infect. Public Health 9, 227 230. doi: 10.1016/j.jiph.2016.04.001

Rowland, R. R. R., Chauhan, V., Fang, Y., Pekosz, A., Kerrigan, M., and Burton, M. D. (2005). Intracellular Localization of the Severe Acute Respiratory Syndrome Coronavirus Nucleocapsid Protein: Absence of Nucleolar Accumulation during Infection and after Expression as a Recombinant Protein in Vero Cells. J. Virol. 79, 11507-11512. doi: 10.1128/ JVI.79.17.11507-11512.2005

Ruan, Q., Yang, K., Wang, W., Jiang, L., and Song, J. (2020). Clinical predictors of mortality due to COVID-19 based on an analysis of data of 150 patients from Wuhan, China. Intensive Care Med. 46, 846-848. doi: 10.1007/s00134-02005991-x

Rudolph, A. R., and Tuthill, C. W. (2010). Treatment or prevention of respiratory viral infections with alpha thymosin peptides. Available at: https://patents. google.com/patent/US20100311656A1/en\#patentCitations (Accessed April 2, 2020).

Russell, B., Moss, C., George, G., Santaolalla, A., Cope, A., Papa, S., et al. (2020). Associations between immune-suppressive and stimulating drugs and novel COVID-19-a systematic review of current evidence. Ecancermedicalscience 14, 1022. doi: 10.3332/ecancer.2020.1022

Russell, C. D., Millar, J. E., and Baillie, J. K. (2020). Clinical evidence does not support corticosteroid treatment for 2019-nCoV lung injury. Lancet 395, $473-$ 475. doi: 10.1016/S0140-6736(20)30317-2

Salazar, E., Perez, K. K., Ashraf, M., Chen, J., Castillo, B., Christensen, P. A., et al. (2020). Treatment of Coronavirus Disease 2019 (COVID-19) Patients with Convalescent Plasma. Am. J. Pathol. 190, 1680-1690. doi: 10.1016/ j.ajpath.2020.05.014

Sangawa, H., Komeno, T., Nishikawa, H., Yoshida, A., Takahashi, K., Nomura, N., et al. (2013). Mechanism of Action of T-705 Ribosyl Triphosphate against Influenza Virus RNA Polymerase. Antimicrobial. Agents Chemother. 57, 52025208. doi: 10.1128/AAC.00649-13

Savarino, A., Boelaert, J. R., Cassone, A., Majori, G., and Cauda, R. (2003). Effects of chloroquine on viral infections: an old drug against today's diseases. Lancet Infect. Dis. 3, 722-727. doi: 10.1016/S1473-3099(03)00806-5

Schögler, A., Kopf, B. S., Edwards, M. R., Johnston, S. L., Casaulta, C., Kieninger, E., et al. (2015). Novel antiviral properties of azithromycin in cystic fibrosis airway epithelial cells. Eur. Respir. J. 45, 428-439. doi: 10.1183/09031936.00102014

Sheahan, T. P., Sims, A. C., Graham, R. L., Menachery, V. D., Gralinski, L. E., Case, J. B., et al. (2017). Broad-spectrum antiviral GS-5734 inhibits both epidemic and zoonotic coronaviruses. Sci. Transl. Med. 9, eaal3653. doi: 10.1126/ scitranslmed.aal3653

Sheahan, T. P., Sims, A. C., Leist, S. R., Schäfer, A., Won, J., Brown, A. J., et al. (2020a). Comparative therapeutic efficacy of remdesivir and combination lopinavir, ritonavir, and interferon beta against MERS-CoV. Nat. Commun. 11, 222. doi: 10.1038/s41467-019-13940-6

Sheahan, T. P., Sims, A. C., Zhou, S., Graham, R. L., Pruijssers, A. J., Agostini, M. L., et al. (2020b). An orally bioavailable broad-spectrum antiviral inhibits SARS-CoV-2 in human airway epithelial cell cultures and multiple coronaviruses in mice. Sci. Trans. Med. 12. doi: 10.1126/scitranslmed.abb5883

Shi, Z., Wei, J., Deng, X., Li, S., Qiu, Y., Shao, D., et al. (2014). Nitazoxanide inhibits the replication of Japanese encephalitis virus in cultured cells and in a mouse model. Virol. J. 11, 10. doi: 10.1186/1743-422X-11-10

Shiryaev, S. A., Mesci, P., Pinto, A., Fernandes, I., Sheets, N., Shresta, S., et al. (2017). Repurposing of the anti-malaria drug chloroquine for Zika Virus treatment and prophylaxis. Sci. Rep. 7, 1-9. doi: 10.1038/s41598-017-15467-6

Shrestha, R., Kharel Sitaula, R., Karki, P., Joshi, S. N., and Rawal, S. (2019). Combined Intravitreal Bevacizumab And Dexamethasone In Bilateral Lupus Retinopathy. Int. Med. Case Rep. J. 12, 329-333. doi: 10.2147/IMCRJ.S220499 
Shvetsov, A. V., Zabrodskaya, Y. A., Nekrasov, P. A., and Egorov, V. V. (2018). Triazavirine supramolecular complexes as modifiers of the peptide oligomeric structure. J. Biomol. Struct. Dynamics 36, 2694-2698. doi: 10.1080/ 07391102.2017.1367329

Sidwell, R. W., Huffman, J. H., Khare, G. P., Allen, L. B., Witkowski, J. T., and Robins, R. K. (1972). Broad-spectrum antiviral activity of Virazole: 1-beta-Dribofuranosyl-1,2,4-triazole-3-carboxamide. Science 177, 705-706. doi: $10.1126 /$ science.177.4050.705

Singhal, T. (2020). A Review of Coronavirus Disease-2019 (COVID-19). Indian J. Pediatr. 87, 281-286. doi: 10.1007/s12098-020-03263-6

Siu, Y. L., Teoh, K. T., Lo, J., Chan, C. M., Kien, F., Escriou, N., et al. (2008). The M, E, and N Structural Proteins of the Severe Acute Respiratory Syndrome Coronavirus Are Required for Efficient Assembly, Trafficking, and Release of Virus-Like Particles. J. Virol. 82, 11318-11330. doi: 10.1128/JVI.01052-08

Skipper, C. P., Pastick, K. A., Engen, N. W., Bangdiwala, A. S., Abassi, M., Lofgren, S. M., et al. (2020). Hydroxychloroquine in Nonhospitalized Adults With Early COVID-19. Ann. Internal Med. M20-4207. doi: 10.7326/M20-4207

Smith, J. R., Rayner, C. R., Donner, B., Wollenhaupt, M., Klumpp, K., and Dutkowski, R. (2011). Oseltamivir in seasonal, pandemic, and avian influenza: a comprehensive review of 10-years clinical experience. Adv. Ther. 28, 927-959. doi: 10.1007/s12325-011-0072-7

Stockman, L. J., Bellamy, R., and Garner, P. (2006). SARS: Systematic review of treatment effects. PloS Med. 3, 1525-1531. doi: 10.1371/journal.pmed.0030343

Stone, J. H., Tuckwell, K., Dimonaco, S., Klearman, M., Aringer, M., Blockmans, D., et al. (2017). Trial of tocilizumab in giant-cell arteritis. New Engl. J. Med. 377, 317-328. doi: 10.1056/NEJMoa1613849

Stuyver, L. J., Whitaker, T., McBrayer, T. R., Hernandez-Santiago, B.II, Lostia, S., Tharnish, P. M., et al. (2003). Ribonucleoside Analogue That Blocks Replication of Bovine Viral Diarrhea and Hepatitis C Viruses in Culture. Antimicrobial. Agents Chemother. 47, 244-254. doi: 10.1128/AAC.47.1.244-254.2003

Su, S., Wong, G., Shi, W., Liu, J., Lai, A. C. K., Zhou, J., et al. (2016). Epidemiology, Genetic Recombination, and Pathogenesis of Coronaviruses. Trends Microbiol. 24, 490-502. doi: 10.1016/j.tim.2016.03.003

Subbarao, K., McAuliffe, J., Vogel, L., Fahle, G., Fischer, S., Tatti, K., et al. (2004). Prior Infection and Passive Transfer of Neutralizing Antibody Prevent Replication of Severe Acute Respiratory Syndrome Coronavirus in the Respiratory Tract of Mice. J. Virol. 78, 3572-3577. doi: 10.1128/ JVI.78.7.3572-3577.2004

Sung, J., Wu, A., Joynt, G., Yuen, K., Lee, N., Chan, P., et al. (2004). Severe acute respiratory syndrome: report of treatment and outcome after a major outbreak. Thorax 59, 414-420. doi: 10.1136/thx.2003.014076

Svetitsky, S., Leibovici, L., and Paul, M. (2009). Comparative efficacy and safety of vancomycin versus teicoplanin: systematic review and meta-analysis. Antimicrob. Agents Chemother. 53, 4069-4079. doi: 10.1128/AAC.00341-09

Tai, W., He, L., Zhang, X., Pu, J., Voronin, D., Jiang, S., et al. (2020). Characterization of the receptor-binding domain (RBD) of 2019 novel coronavirus: implication for development of RBD protein as a viral attachment inhibitor and vaccine. Cell Mol. Immunol., 1-8, 17. doi: 10.1038/ s41423-020-0400-4

Tan, E. L. C., Ooi, E. E., Lin, C.-Y., Tan, H. C., Ling, A. E., Lim, B., et al. (2004). Inhibition of SARS Coronavirus Infection In Vitro with Clinically Approved Antiviral Drugs. Emerg. Infect. Dis. 10, 581-586. doi: 10.3201/eid1004.030458

Tani, H., Komeno, T., Fukuma, A., Fukushi, S., Taniguchi, S., Shimojima, M., et al. (2018). Therapeutic effects of favipiravir against severe fever with thrombocytopenia syndrome virus infection in a lethal mouse model: Doseefficacy studies upon oral administration. PloS One 13, e0206416. doi: 10.1371/ journal.pone.0206416

Tao, J., Song, Z., Yang, L., Huang, C., Feng, A., and Man, X. Emergency management for preventing and controlling nosocomial infection of the 2019 novel coronavirus: implications for the dermatology department. Br. J. Dermatol. 182, 1477-1478. doi: 10.1111/bjd.19011

Tay, M. Y. F., Fraser, J. E., Chan, W. K. K., Moreland, N. J., Rathore, A. P., Wang, C., et al. (2013). Nuclear localization of dengue virus (DENV) 1-4 nonstructural protein 5; protection against all 4 DENV serotypes by the inhibitor Ivermectin. Antiviral Res. 99, 301-306. doi: 10.1016/j.antiviral.2013.06.002

Tchesnokov, E. P., Feng, J. Y., Porter, D. P., and Götte, M. (2019). Mechanism of Inhibition of Ebola Virus RNA-Dependent RNA Polymerase by Remdesivir. Viruses 11, 326. doi: 10.3390/v11040326
Te, H. S., Randall, G., and Jensen, D. M. (2007). Mechanism of Action of Ribavirin in the Treatment of Chronic Hepatitis C. Gastroenterol. Hepatol. (N. Y.) 3, 218-225.

The RECOVERY Collaborative Group (2020). Dexamethasone in Hospitalized Patients with Covid-19 - Preliminary Report. New Engl. J. Med. doi: 10.1056/ NEJMoa2021436

Timani, K. A., Liao, Q., Ye, L., Zeng, Y., Liu, J., Zheng, Y., et al. (2005). Nuclear/ nucleolar localization properties of C-terminal nucleocapsid protein of SARS coronavirus. Virus Res. 114, 23-34. doi: 10.1016/j.virusres.2005.05.007

Toots, M., Yoon, J.-J., Cox, R. M., Hart, M., Sticher, Z. M., Makhsous, N., et al. (2019). Characterization of orally efficacious influenza drug with high resistance barrier in ferrets and human airway epithelia. Sci. Transl. Med. 11, eaax5866. doi: 10.1126/scitranslmed.aax5866

Tran, D. H., Sugamata, R., Hirose, T., Suzuki, S., Noguchi, Y., Sugawara, A., et al. (2019). Azithromycin, a 15-membered macrolide antibiotic, inhibits influenza $\mathrm{A}(\mathrm{H} 1 \mathrm{~N} 1)$ pdm09 virus infection by interfering with virus internalization process. J. Antibiot. 72, 759-768. doi: 10.1038/s41429-019-0204-x

Tricou, V., Minh, N. N., Van, T. P., Lee, S. J., Farrar, J., Wills, B., et al. (2010). A randomized controlled trial of chloroquine for the treatment of dengue in Vietnamese adults. PloS Negl. Trop. Dis. 4, e785. doi: 10.1371/journal.pntd.0000785

Trombetta, H., Faggion, H. Z., Leotte, J., Nogueira, M. B., Vidal, L. R. R., and Raboni, S. M. (2016). Human coronavirus and severe acute respiratory infection in Southern Brazil. Pathog. Glob. Health 110, 113-118. doi: 10.1080/20477724.2016.1181294

Tsai, W.-P., Nara, P. L., Kung, H.-F., and Oroszlan, S. (1990). Inhibition of Human Immunodeficiency Virus Infectivity by Chloroquine. AIDS Res. Hum. Retroviruses 6, 481-489. doi: 10.1089/aid.1990.6.481

Urakova, N., Kuznetsova, V., Crossman, D. K., Sokratian, A., Guthrie, D. B., Kolykhalov, A. A., et al. (2018). B-d-N4-Hydroxycytidine Is a Potent Antialphavirus Compound That Induces a High Level of Mutations in the Viral Genome. J. Virol. 92, e01965-17. doi: 10.1128/JVI.01965-17

Velazquez-Salinas, L., Verdugo-Rodriguez, A., Rodriguez, L. L., and Borca, M. V. (2019). The Role of Interleukin 6 During Viral Infections. Front. Microbiol. 10, 1057. doi: $10.3389 /$ fmicb. 2019.01057

Ventre, K., and Randolph, A. (2004). Ribavirin for respiratory syncytial virus infection of the lower respiratory tract in infants and young children. Cochrane Database Syst. Rev., CD000181. doi: 10.1002/14651858.CD000181.pub2

Vigerust, D. J., and McCullers, J. A. (2007). Chloroquine is effective against influenza A virus in vitro but not in vivo. Influenza Other Respir. Viruses 1, 189-192. doi: 10.1111/j.1750-2659.2007.00027.x

Vincent, M. J., Bergeron, E., Benjannet, S., Erickson, B. R., Rollin, P. E., Ksiazek, T. G., et al. (2005). Chloroquine is a potent inhibitor of SARS coronavirus infection and spread. Virol. J. 2, 69. doi: 10.1186/1743-422X-2-69

Viveiros Rosa, S. G., and Santos, W. C. (2020). Clinical trials on drug repositioning for COVID-19 treatment. Rev. Panam. Salud Publica 44, e40. doi: 10.26633/ RPSP. 2020.40

Wagstaff, K. M., Sivakumaran, H., Heaton, S. M., Harrich, D., and Jans, D. A. (2012). Ivermectin is a specific inhibitor of importin $\alpha / \beta$-mediated nuclear import able to inhibit replication of HIV-1 and dengue virus. Biochem. J. 443, 851-856. doi: 10.1042/BJ20120150

Wang, H., Yang, P., Liu, K., Guo, F., Zhang, Y., Zhang, G., et al. (2008). SARS coronavirus entry into host cells through a novel clathrin- and caveolaeindependent endocytic pathway. Cell Res. 18, 290-301. doi: 10.1038/cr.2008.15

Wang, Q., Liu, X., Wang, Q., Zhang, Y., Jiang, J., Guo, X., et al. (2011). FNC, a novel nucleoside analogue inhibits cell proliferation and tumor growth in a variety of human cancer cells. Biochem. Pharmacol. 81, 848-855. doi: 10.1016/ j.bcp.2011.01.001

Wang, L.-F., Lin, Y.-S., Huang, N.-C., Yu, C.-Y., Tsai, W.-L., Chen, J.-J., et al. (2015). Hydroxychloroquine-Inhibited Dengue Virus Is Associated with Host Defense Machinery. J. Interferon Cytokine Res. 35, 143-156. doi: 10.1089/ jir.2014.0038

Wang, C., Liao, C., Zhang, W., Li, D., and Chen, P. (2016). Influenza Inactive Virus Vaccine with the Fusion Peptide (rTo1- BP5) Enhances Protection Against Influenza Through Humoral and Cell-Mediated Immunity. Steps Forwards Diagnosing Controlling Influenza. doi: 10.5772/64403

Wang, Y., Cui, R., Li, G., Gao, Q., Yuan, S., Altmeyer, R., et al. (2016). Teicoplanin inhibits Ebola pseudovirus infection in cell culture. Antiviral Res. 125, 1-7. doi: 10.1016/j.antiviral.2015.11.003 
Wang, D., Hu, B., Hu, C., Zhu, F., Liu, X., Zhang, J., et al. (2020). Clinical Characteristics of 138 Hospitalized Patients With 2019 Novel Coronavirus-Infected Pneumonia in Wuhan, China. JAMA 323, 1061-1069. doi: 10.1001/jama.2020.1585

Wang, L., Wang, Y., Ye, D., and Liu, Q. (2020). Review of the 2019 novel coronavirus (SARS-CoV-2) based on current evidence. Int. J. Antimicrob. Agents 55, 105948. doi: 10.1016/j.ijantimicag.2020.105948

Wang, M., Cao, R., Zhang, L., Yang, X., Liu, J., Xu, M., et al. (2020). Remdesivir and chloroquine effectively inhibit the recently emerged novel coronavirus, (2019-nCoV) in vitro. Cell Res. 30, 269-271. doi: 10.1038/s41422-020-0282-0

Wang, Q., Xu, B., Fan, K., Wu, J., and Wang, T. (2020). Inflammation suppression by dexamethasone via inhibition of CD147-mediated NF-KB pathway in collageninduced arthritis rats. Mol. Cell. Biochem. doi: 10.1007/s11010-020-03808-5

Wang, X., Cao, R., Zhang, H., Liu, J., Xu, M., Hu, H., et al. (2020). The antiinfluenza virus drug, arbidol is an efficient inhibitor of SARS-CoV-2 in vitro. Cell Discovery 6, 1-5. doi: 10.1038/s41421-020-0169-8

Wang, Y., Zhang, D., Du, G., Du, R., Zhao, J., Jin, Y., et al. (2020). Remdesivir in adults with severe COVID-19: a randomised, double-blind, placebo-controlled, multicentre trial. Lancet. 395, 1569-1578. doi: 10.1016/S0140-6736(20)31022-9

Wang, Z., Chen, X., Lu, Y., Chen, F., and Zhang, W. (2020a). Clinical characteristics and therapeutic procedure for four cases with 2019 novel coronavirus pneumonia receiving combined Chinese and Western medicine treatment. BioSci. Trends. 14, 64-68. doi: 10.5582/bst.2020.01030

Wang, Z., Yang, B., Li, Q., Wen, L., and Zhang, R. (2020b). Clinical Features of 69 Cases With Coronavirus Disease 2019 in Wuhan, China. Clin. Infect. Dis. 71, 769-777. doi: 10.1093/cid/ciaa272

Warren, T. K., Jordan, R., Lo, M. K., Ray, A. S., Mackman, R. L., Soloveva, V., et al. (2016). Therapeutic Efficacy of the Small Molecule GS-5734 against Ebola Virus in Rhesus Monkeys. Nature 531, 381-385. doi: 10.1038/nature17180

White, C. A. (2004). Nitazoxanide: a new broad spectrum antiparasitic agent. Expert Rev. Anti Infect. Ther. 2, 43-49. doi: 10.1586/14787210.2.1.43

Williamson, B. N., Feldmann, F., Schwarz, B., Meade-White, K., Porter, D. P., Schulz, J., et al. (2020). Clinical benefit of remdesivir in rhesus macaques infected with SARS-CoV-2. Nature, 1-7. doi: 10.1038/s41586-020-2423-5

Wong, C. K., Lam, C. W. K., Wu, A. K. L., Ip, W. K., Lee, N. L. S., Chan, I. H. S., et al. (2004). Plasma inflammatory cytokines and chemokines in severe acute respiratory syndrome. Clin. Exp. Immunol. 136, 95-103. doi: 10.1111/j.13652249.2004.02415.x

Wong, M. C., Cregeen, S. J. J., Ajami, N. J., and Petrosino, J. F. (2020). Evidence of recombination in coronaviruses implicating pangolin origins of $\mathrm{nCoV}-2019$. bioRxiv 2020, 2.07.939207. doi: 10.1101/2020.02.07.939207

Woo, P.C. Y., Lau, S. K. P., Lam, C. S. F., Lau, C. C. Y., Tsang, A. K. L., Lau, J. H. N., et al. (2012). Discovery of Seven Novel Mammalian and Avian Coronaviruses in the Genus Deltacoronavirus Supports Bat Coronaviruses as the Gene Source of Alphacoronavirus and Betacoronavirus and Avian Coronaviruses as the Gene Source of Gammacoronavirus and Deltacoronavirus. J. Virol. 86, 3995-4008. doi: 10.1128/JVI.06540-11

Woodrick, R. S., and Ruderman, E. M. (2011). Interleukin 6 inhibition: RA and beyond. Bull. NYU Hosp. Joint Dis. 69, 225-229.

World Health Organization Pneumonia of unknown cause - China. Available at: http://www.who.int/csr/don/05-january-2020-pneumonia-of-unkown-causechina/en/ (Accessed April 22, 2020).

World Health Organization (2020a). Coronavirus disease 2019 (COVID-19) Situation Report - 46. Available at: https://www.who.int/emergencies/ diseases/novel-coronavirus-2019/situation-reports (Accessed April 16, 2020).

World Health Organization (2020b). Coronavirus Disease (COVID-19) - events as they happen. Available at: https://www.who.int/emergencies/diseases/novelcoronavirus-2019/events-as-they-happen (Accessed April 23, 2020).

World Health Organization (2020c). Coronavirus Disease (COVID-19) Situation Reports. Available at: https://www.who.int/emergencies/diseases/novelcoronavirus-2019/situation-reports (Accessed July 10, 2020).

World Health Organization (2020d). WHO discontinues hydroxychloroquine and lopinavir/ritonavir treatment arms for COVID-19. Available at: https://www.who. int/news-room/detail/04-07-2020-who-discontinues-hydroxychloroquine-andlopinavir-ritonavir-treatment-arms-for-covid-19 (Accessed July 10, 2020).

Wu, C., Liu, Y., Yang, Y., Zhang, P., Zhong, W., Wang, Y., et al. (2020). Analysis of therapeutic targets for SARS-CoV-2 and discovery of potential drugs by computational methods. Acta Pharm. Sin. B. 10, 766-788. doi: 10.1016/ j.apsb.2020.02.008
Wulan, W. N., Heydet, D., Walker, E. J., Gahan, M. E., and Ghildyal, R. (2015). Nucleocytoplasmic transport of nucleocapsid proteins of enveloped RNA viruses. Front. Microbiol. 6, 553. doi: 10.3389/fmicb.2015.00553

Xu, X., Han, M., Li, T., Sun, W., Wang, D., Fu, B., et al. (2020). Effective treatment of severe COVID-19 patients with tocilizumab. PNAS 117, 10970-10975. doi: 10.1073/pnas.2005615117

Yamada, K., Noguchi, K., Komeno, T., Furuta, Y., and Nishizono, A. (2016). Efficacy of Favipiravir (T-705) in Rabies Postexposure Prophylaxis. J. Infect. Dis. 213, 1253-1261. doi: 10.1093/infdis/jiv586

Yamamoto, M., Matsuyama, S., Li, X., Takeda, M., Kawaguchi, Y., Inoue, J., et al. (2016). Identification of Nafamostat as a Potent Inhibitor of Middle East Respiratory Syndrome Coronavirus S Protein-Mediated Membrane Fusion Using the Split-Protein-Based Cell-Cell Fusion Assay. Antimicrob. Agents Chemother. 60, 6532-6539. doi: 10.1128/AAC.01043-16

Yamasmith, E., Avirutnan, P., Mairiang, D., Tanrumluk, S., Suputtamongkol, Y., Saleh-arong, F. A., et al. (2018). Efficacy and Safety of Ivermectin against Dengue Infection: A Phase III, Randomized, Double-blind, Placebo-controlled Trial 1. The 34th Annual Meeting The Royal College of Physicians of Thailand.

Yamaya, M., Shimotai, Y., Hatachi, Y., Lusamba Kalonji, N., Tando, Y., Kitajima, Y., et al. (2015). The serine protease inhibitor camostat inhibits influenza virus replication and cytokine production in primary cultures of human tracheal epithelial cells. Pulm. Pharmacol. Ther. 33, 66-74. doi: 10.1016/.jpupt.2015.07.001

Yan, D., Liu, X.-Y., Zhu, Y., Huang, L., Dan, B., Zhang, G., et al. (2020). Factors associated with prolonged viral shedding and impact of Lopinavir/Ritonavir treatment in hospitalised non-critically ill patients with SARS-CoV-2 infection. Eur. Respir. J. 56, 2000799. doi: 10.1183/13993003.00799-2020

Yang, Z.-Y., Huang, Y., Ganesh, L., Leung, K., Kong, W.-P., Schwartz, O., et al. (2004). pH-Dependent Entry of Severe Acute Respiratory Syndrome Coronavirus Is Mediated by the Spike Glycoprotein and Enhanced by Dendritic Cell Transfer through DC-SIGN. J. Virol. 78, 5642-5650. doi: 10.1128/JVI.78.11.5642-5650.2004

Yang, C., Ke, C., Yue, D., Li, W., Hu, Z., Liu, W., et al. (2020). Effectiveness of Arbidol for COVID-19 Prevention in Health Professionals. Front. Public Health 8, 249. doi: 10.3389/fpubh.2020.00249

Yang, S. N. Y., Atkinson, S. C., Wang, C., Lee, A., Bogoyevitch, M. A., Borg, N. A., et al. (2020). The broad spectrum antiviral ivermectin targets the host nuclear transport importin $\alpha / \beta 1$ heterodimer. Antiviral Res. 177, 104760. doi: 10.1016/ j.antiviral.2020.104760

Yao, X., Ye, F., Zhang, M., Cui, C., Huang, B., Niu, P., et al. (2020). In Vitro Antiviral Activity and Projection of Optimized Dosing Design of Hydroxychloroquine for the Treatment of Severe Acute Respiratory Syndrome Coronavirus 2 (SARS-CoV-2). Clin. Infect. Dis. 71, 732-739. doi: 10.1093/cid/ciaa237

Yasir, M., Goyal, A., Bansal, P., and Sonthalia, S. (2020). "Corticosteroid Adverse Effects," in StatPearls (Treasure Island (FL): StatPearls Publishing).

Yoon, J.-J., Toots, M., Lee, S., Lee, M.-E., Ludeke, B., Luczo, J. M., et al. (2018). Orally Efficacious Broad-Spectrum Ribonucleoside Analog Inhibitor of Influenza and Respiratory Syncytial Viruses. Antimicrob. Agents Chemother. 62, e00766-18. doi: 10.1128/AAC.00766-18

Yuan, M., Wu, N. C., Zhu, X., Lee, C.-C. D., So, R. T. Y., Lv, H., et al. (2020). A highly conserved cryptic epitope in the receptor-binding domains of SARSCoV-2 and SARS-CoV Science. 368, 630-633. doi: 10.1126/science.abb7269

Zaki, A. M., van Boheemen, S., Bestebroer, T. M., Osterhaus, A. D. M. E., and Fouchier, R. A. M. (2012). Isolation of a novel coronavirus from a man with pneumonia in Saudi Arabia. N. Engl. J. Med. 367, 1814-1820. doi: 10.1056/ NEJMoa1211721

Zhang, S., Yi, C., Li, C., Zhang, F., Peng, J., Wang, Q., et al. (2019). Chloroquine inhibits endosomal viral RNA release and autophagy-dependent viral replication and effectively prevents maternal to fetal transmission of Zika virus. Antiviral Res. 169, 104547. doi: 10.1016/j.antiviral.2019.104547

Zhang, L., Lin, D., Sun, X., Curth, U., Drosten, C., Sauerhering, L., et al. (2020). Crystal structure of SARS-CoV-2 main protease provides a basis for design of improved $\alpha$ ketoamide inhibitors. Science 368, 409-412. doi: 10.1126/science.abb3405

Zhang, T., Wu, Q., and Zhang, Z. (2020). Probable Pangolin Origin of SARS-CoV2 Associated with the COVID-19 Outbreak. Curr. Biol. 30, 1346-1351.e2. doi: 10.1016/j.cub.2020.03.022

Zhang, X., Song, K., Tong, F., Fei, M., Guo, H., Lu, Z., et al. (2020). First case of COVID19 in a patient with multiple myeloma successfully treated with tocilizumab. Blood $A d v$. 4, 1307-1310. doi: 10.1182/bloodadvances.2020001907 
Zhang, J., Ma, X., Yu, F., Liu, J., Zou, F., Pan, T., et al. (2020a). Teicoplanin potently blocks the cell entry of 2019-nCoV. bioRxiv 2020:2.05.935387. doi: 10.1101/2020.02.05.935387

Zhang, J., Wang, W., Peng, B., Peng, W., Zhang, Y., Wang, Y., et al. (2020b). Potential of Arbidol for Post-exposure Prophylaxis of COVID-19 Transmission-A Preliminary Report of a Retrospective Cohort Study. Curr. Med. Sci. 40, 1-6. doi: 10.1007/s11596-020-2203-3

Zhang, J., Wang, W., Peng, B., Peng, W., Zhang, Y., Wang, Y., et al. (2020c). Potential of Arbidol for Post-exposure Prophylaxis of COVID-19 Transmission. Curr. Med. Sci. 40, 480-485. doi: 10.12074/202002.00065

Zhong, N. S., Zheng, B. J., Li, Y. M., Poon, , L. L. M., Xie, Z. H., Chan, K. H., et al. (2003). Epidemiology and cause of severe acute respiratory syndrome (SARS) in Guangdong, People's Republic of China, in February 2003. Lancet 362, 1353-1358. doi: 10.1016/s0140-6736(03)14630-2

Zhou, Y., Zhang, Y., Yang, X., Zhao, J., Zheng, L., Sun, C., et al. (2012). Novel nucleoside analogue FNC is effective against both wild-type and lamivudineresistant HBV clinical isolates. Antivir. Ther. (Lond.) 17, 1593-1599. doi: 10.3851/ IMP2292

Zhou, Y. Vedantham, P. Lu, K. Agudelo, J. Carrion, R. Jr., Nunneley, J. W., et al. (2015). Protease inhibitors targeting coronavirus and filovirus entry. Antiviral Res. 116, 76-84. doi: 10.1016/j.antiviral.2015.01.011

Zhou, N., Pan, T., Zhang, J., Li, Q., Zhang, X., Bai, C., et al. (2016). Glycopeptide Antibiotics Potently Inhibit Cathepsin L in the Late Endosome/Lysosome and Block the Entry of Ebola Virus, Middle East Respiratory Syndrome Coronavirus (MERS-CoV), and Severe Acute Respiratory Syndrome Coronavirus (SARS-CoV). J. Biol. Chem. 291, 9218-9232. doi: 10.1074/jbc.M116.716100
Zhou, P., Yang, X.-L., Wang, X.-G., Hu, B., Zhang, L., Zhang, W., et al. (2020). A pneumonia outbreak associated with a new coronavirus of probable bat origin. Nature 579, 270-273. doi: 10.1038/s41586-020-2012-7

Zhou, Y., He, X., Zhang, J., Xue, Y., Liang, M., Yang, B., et al. (2020). Prolonged SARS-CoV-2 Viral Shedding in Patients with COVID-19 was Associated with Delayed Initiation of Arbidol Treatment: a retrospective cohort study. medRxiv 2020. doi: 10.1101/2020.06.09.20076646

Zhu, Y.-Z., Xu, Q.-Q., Wu, D.-G., Ren, H., Zhao, P., Lao, W.-G., et al. (2012). Japanese Encephalitis Virus Enters Rat Neuroblastoma Cells via a pHDependent, Dynamin and Caveola-Mediated Endocytosis Pathway. J. Virol. 86, 13407-13422. doi: 10.1128/JVI.00903-12

Zhu, N., Zhang, D., Wang, W., Li, X., Yang, B., Song, J., et al. (2020). A Novel Coronavirus from Patients with Pneumonia in China 2019. N. Engl. J. Med. 382, 727-733. doi: 10.1056/NEJMoa2001017

Conflict of Interest: The authors declare that the research was conducted in the absence of any commercial or financial relationships that could be construed as a potential conflict of interest.

Copyright (c) 2020 Kaddoura, AlIbrahim, Hijazi, Soudani, Audi, Alkalamouni, Haddad, Eid and Zaraket. This is an open-access article distributed under the terms of the Creative Commons Attribution License (CC BY). The use, distribution or reproduction in other forums is permitted, provided the original author(s) and the copyright owner(s) are credited and that the original publication in this journal is cited, in accordance with accepted academic practice. No use, distribution or reproduction is permitted which does not comply with these terms. 